\title{
TECNOLOGÍA DE LA COMUNICACIÓN Y SISTEMAS DE CO- MUNICACIÓN EN EL LENGUAJE. REVISIÓN SISTEMÁTICA DESDE LA FONOAUDIOLOGÍA
}

\author{
Use of communication technology and communication systems in \\ language. A look after phonoaudiology.
}

Pérez R Ginna $V^{(1)}$, Martínez M Aura J(2), Peñaloza M Zayda $R^{(3)}$, Ríos F Niyireth $L^{(4)}$, Ortega $O$ Yury K. Zambrano Laura B. Martínez O Jennyfer A. Sinuco M Yulieth.

\section{RESUMEN}

INTRODUCCIÓN: El objetivo de este estudio, es analizar la evidencia científica disponible en la intervención de personas en situación de discapacidad y la comunicación aumentativa y alternativa, a fin de generar avances significativos en el área de la Fonoaudiología. MÉTODOS: revisión sistemática de tipo descriptivo en donde se realiza una búsqueda en diferentes bases de datos en una línea de tiempo de 10 años siendo en estudios con seres humanos en situación de discapacidad. RESULTADOS: Esta revisión permitió evidenciar los diferentes recursos disponibles en los niveles Fonético Fonológico, Semántico, Morfosintáctico y utilización de tecnología de la comunicación en el lenguaje para personas en situación de discapacidad. ANÁLISIS Y DISCUSIÓN: En los procesos de intervención que realiza el profesional en fonoaudiología se destaca actualmente la importancia del uso de la tecnología como herramienta que permita abordar de forma eficiente las dificultades que se puedan presentar en el campo de la comunicación. CONCLUSIONES: Es necesario ahondar en investigaciones para usuarios de habla hispana con el fin de fortalecer el desarrollo del lenguaje y/o crear estrategias de intervención que permitan mejorar el desempeño comunicativo en un contexto específico.

PALABRAS CALVE: Equipos de comunicación para personas con Discapacidad, Intervención, Fonética, Semántica, Sintáctico (no Decs).

\begin{abstract}
INTRODUCTION: The objective of this study is to analyze the scientific evidence available in the intervention of people with disabilities and augmentative and alternative communication, in order to generate significant advances in the area of Speech Therapy. METHODS: systematic review of the type; RESULTS: This review made it possible to highlight the different resources available in the Phonological, Phonological, Semantic and Syntactic levels and the use of communication technology in language for people with a disability. ANALYSIS AND DISCUSSION: In the intervention processes carried out by the speech and hearing professionals, the importance of the use of technology as a tool to efficiently address the difficulties that may arise in the field of communication is highlighted. CONCLUSIONS: It is necessary to delve into research for Spanish-speaking users in order to strengthen language development and / or create intervention strategies to improve communicative performance in a specific context.
\end{abstract}

KEY WORDS: Communication Equipment for the Disabled, Wireless Technology, Intervention, Phonetics, Semantics.

(1) Fonoaudióloga. Magister en Educación. Docente de la Universidad de Pamplona (2) Fonoaudióloga. Especialista en Pedagogía Universitaria. Magister en Intervención Educativa y Psicológica (3) Fonoaudióloga. Especialista en Psicopedagogía Especial (4) Fonoaudióloga. Especialista en Audiología. 


\section{INTRODUCCIÓN}

La Comunicación Humana se asume como el proceso de interacción bidireccional que posibilita el acceso a la información, el aprendizaje, y la socialización con el medio; teniendo en cuenta las dimensiones intrapersonal, interpersonal y sociocultural. Al presentarse un desorden en la comunicación afectando los procesos de expresión y comprensión se genera una situación específica que puede ser transitoria o permanente, y que debe ser intervenida planteando soluciones o alternativas que favorezca la calidad de vida.

En la actualidad para fundamentar los procesos de investigación se hace necesario tener las evidencias científicas disponibles en las áreas disciplinares de la fonoaudiología; y particularmente para este proceso que se plantea se realizará una indagación de evidencia clínica, las relaciones de variables referentes a la fonética y fonología, semántica y morfosintaxis; así como, las referencias frente al uso de tecnología para la comunicación en población con necesidades educativas especiales (NEE) y/o población en situación de discapacidad, teniendo como herramienta la utilización de la tecnología como estrategia de intervención.

Sobre la base de las consideraciones anteriores, se entiende que el lenguaje es la capacidad de expresar nuestras ideas, pensamientos y emociones a través de signos o gestos, y en el ser humano este proceso cumple con dos claros objetivos; ser un medio de comunicación y servir de herramienta o instrumento cognitivo. 1

Cuando se hace referencia al lenguaje se puede clasificar en tres dimensiones: Forma (fonética y fonología, morfología y sintaxis), contenido (semántica) y uso (pragmática); de igual forma también abarca dos procesos fundamentales como la comprensión y la expresión, por ello en la presente investigación se analizarán las evidencias científicas de cada componente del lenguaje y su relación con las tecnologías de la comunicación. A continuación, se presentan dos ramas de la lingüística como lo son la fonética y la fonología; La fonética se ocupa de las características físicas de los sonidos, los rasgos laríngeos, el punto y el modo de articulación, mientras que la fonología estudia la manera en que se organiza el sistema de sonidos que conforman el lenguaje. Por lo tanto, en la adquisición fonética-fonológica existe un orden de aparición y unas estructuras de desarrollo muy definidas debido a que la rapidez de adquisición varía de unos niños a otros. 2

En segundo plano Gutiérrez3 define la semántica como una extensión que abarca el contenido del lenguaje representado en el estudio significativo de las palabras, y sus combinaciones, asimismo hace referencia a los aspectos del significado, sentido o interpretación de los signos como representaciones para poder realizar una comunicación.

En el desarrollo del lenguaje otro aspecto importante es la morfosintaxis, radica en que permite a los niños codificar y comunicarse sobre lo que ocurre en su entorno, lo que a su vez amplía las posibilidades comunicativas que ofrecen las palabras individuales, realizando procesos de organización y estructuración de sus enunciados por medio de la combinación de las palabras de forma sistemática para crear frases que contengan reglas gramaticales dando coherencia y cohesión en sus producciones lingüísticas. 4

Cuando alguno de estos componentes se ve alterado, ya sea por disfunción cerebral, inmadurez o retraso, entre otros, el rol del terapeuta será buscar las alternativas que ayuden y/o fortalezcan esos componentes; es aquí donde radica la importancia de conocer qué nuevas estrategias de intervención a través de la tecnología se están desarrollando en la actualidad o si existen evidencias clínicas de uso, que nos permitan hacer una intervención encaminada a mejorar y mantener la integralidad del lenguaje.5 Por otra parte Según Bacalleo,6 los usos de las tecnologías de la información y la comunicación han transformado un campo relevante como es la investigación social en particular para la comunicación, cuyo propósito es el acceso de las personas con discapacidad a procesos de intercambio comunicativo, existiendo una relación que da un doble sentido; por una parte, la accesibilidad de este tipo de población a dichas tecnologías, y, por otra hacen que la inclusión social no sea un factor negativo en la vida de las personas con esta condi- 
Pérez R Ginna V, Martínez M Aura J, Peñaloza M Zayda R, Ortega O Yury K, Sinuco M Yulieth, Zambrano Laura B, Martínez O Jennyfer A.

ción, dando la posibilidad de que los individuos alcancen una dimensión incluyente en la sociedad. Es evidente entonces que la comunicación humana y la tecnología contemplan una relación de gran interés para aquellas personas con discapacidad, como medio para generar nuevas alternativas, traspasando barreras y mostrando así una oportunidad de comunicación y relación con el entorno, potenciando sus capacidades, independencia y lo más importante, estimulando la comunicación e interacción con su entorno, social, escolar, sociocultural y familiar.

Es por todo lo antes enunciado y analizado que se plantea la pregunta de investigación ¿Qué evidencias científicas se encuentran del uso de las tecnologías en el lenguaje y particularmente, en el desarrollo de las habilidades lingüísticas de los componentes Fonético-fonológico, Semántico y Morfosintáctico; así como el uso de tecnologías para la comunicación en población en situación de discapacidad.

\section{MÉTODOS}

La metodología de investigación es descriptiva en la que se plantea la indagación, recolección, organización y análisis de la información científica establecida en una ventana de tiempo de 10 años, se pretende establecer las evidencias que se han generado en el ámbito de salud, particularmente en la utilización de las tecnologías para la terapéutica en comunicación y lenguaje. Esta recolección de evidencias se plantea a través de ejercicios de Revisión sistemática que establece la identificación de variables y análisis, en el cruce de dichas variables para llegar a establecer que hallazgos científicos, teóricos e investigativos se presentan a la comunidad científica. El proceso de indagación de la información en las diferentes bases de datos tuvo un periodo de ocurrencia de 4 meses en el primer semestre del 2017, la información recogida tiene un análisis descriptivo a través de la categorización de conceptos y teorías recurrentes.

Por ello las variables a analizar en la primera fase se enuncian en las siguientes tablas:

Tabla 1. Cruce de variables componente fonético - fonológico

\begin{tabular}{llll}
\hline Variable Independiente & Variable Dependiente & Cruces de Variables \\
\hline Intervención +fonética-fonológica & $\begin{array}{l}\text { Equipos para la comunicación en } \\
\text { personas con discapacidad. }\end{array}$ & Intervención + Fonético- fonológico. \\
& $\begin{array}{l}\text { Equipos para la comunicación en } \\
\text { personas con discapacidad. }\end{array}$ & Comunicación+fonético-fonológico \\
\hline comunicación +fonética-fonológica & y & & \\
\hline alternativa fonética-fonológica & Eersonas con discapacidad. & alternativa+fonético-fonológico & y \\
\hline tecnología + fonético-fonológico & Equipos para la comunicación en & tecnología+fonético-fonológico \\
& personas con discapacidad. & \\
\hline
\end{tabular}

Fuente: Los autores 
Tabla 2. Relación variable independientes, dependientes con relación a los cruces utilizados en los aspectos semánticos.

\begin{tabular}{|c|c|c|}
\hline Variable Independiente & Variable Dependiente & Cruces de Variables \\
\hline Semántica & $\begin{array}{l}\text { Equipos para la comunicación en } \\
\text { personas con discapacidad. }\end{array}$ & $\begin{array}{l}\text { semántica + Equipos para la } \\
\text { comunicación en personas con } \\
\text { discapacidad. }\end{array}$ \\
\hline Semántica + comunicación & $\begin{array}{l}\text { Equipos para la comunicación en } \\
\text { personas con discapacidad. }\end{array}$ & $\begin{array}{l}\text { Semántica + comunicación +Equipos } \\
\text { para la comunicación en personas con } \\
\text { discapacidad. }\end{array}$ \\
\hline semántica + comunicación alternativa & $\begin{array}{l}\text { Equipos para la comunicación en } \\
\text { personas con discapacidad. }\end{array}$ & $\begin{array}{l}\text { semántica + comunicación alternativa } \\
+ \text { Equipos para la comunicación en } \\
\text { personas con discapacidad. }\end{array}$ \\
\hline $\begin{array}{l}\text { semántica + comunicación } \\
\text { aumentativa }\end{array}$ & $\begin{array}{l}\text { Equipos para la comunicación en } \\
\text { personas con discapacidad. }\end{array}$ & $\begin{array}{l}\text { semántica }+ \text { comunicación } \\
\text { aumentativa }+ \text { Equipos para la } \\
\text { comunicación en personas con } \\
\text { discapacidad. }\end{array}$ \\
\hline
\end{tabular}

Fuente: Los autores

Tabla 3. Variables del componente sintáctico

\begin{tabular}{lll}
\hline Variable Independiente & Variable Dependiente & Cruces de Variables \\
\hline Comunicación & Sintaxis & Comunicación+sintaxis [majr] \\
\hline Tecnología & Sintaxis & Tecnologia+sintaxis [majr] \\
\hline Comunicación alternativa & Sintaxis & Comunicación alternativa+sintaxis [majr] \\
\hline Comunicación aumentativa & Sintaxis & Comunicación aumentativa+sintaxis[majr] \\
\hline Intervención & & Intervención+sintaxis[majr] \\
\hline Fuente: los autores & Sintaxis &
\end{tabular}


Pérez R Ginna V, Martínez M Aura J, Peñaloza M Zayda R, Ortega O Yury K, Sinuco M Yulieth, Zambrano Laura B, Martínez O Jennyfer A.

Tabla 4. Cruce de variables equipos de comunicación para personas con discapacidad

\begin{tabular}{|c|c|c|c|c|}
\hline Variable Independiente & & Variable Dependiente & & Cruces de Variables \\
\hline $\begin{array}{l}\text { comunicación aumentativa } \\
\text { alternativa }\end{array}$ & $y$ & $\begin{array}{l}\text { Equipos de Comunicación } \\
\text { Personas con Discapacidad. }\end{array}$ & para & $\begin{array}{l}\text { comunicación } \\
\text { alternativa }+\begin{array}{c}\text { aumentativa } \\
\text { equipos }\end{array} \\
\text { comunicación. }\end{array}$ \\
\hline desordenes comunicativos & & $\begin{array}{l}\text { Equipos de Comunicación } \\
\text { Personas con Discapacidad. }\end{array}$ & para & $\begin{array}{l}\text { desordenes comunicativos tequipos } \\
\text { de comunicación. }\end{array}$ \\
\hline Technology for communication & & $\begin{array}{l}\text { Equipos de Comunicación } \\
\text { Personas con Discapacidad. }\end{array}$ & para & $\begin{array}{l}\text { Technology } \\
\text { communication+equipos } \\
\text { comunicación. }\end{array}$ \\
\hline Communication strategies & & $\begin{array}{l}\text { Equipos de Comunicación } \\
\text { Personas con Discapacidad. }\end{array}$ & & $\begin{array}{l}\text { Communication strategies +Equipos } \\
\text { de Comunicación para Personas con } \\
\text { Discapacidad. }\end{array}$ \\
\hline
\end{tabular}

Fuente: los autores

\section{RESULTADOS}

A continuación, se muestran las siguientes tablas y los resultados que se evidenciaron después de la búsqueda realizada según el cruce de variables y el respectivo componente analizado.

Iniciando con el componente Fonético Fonológico se establece la siguiente información:

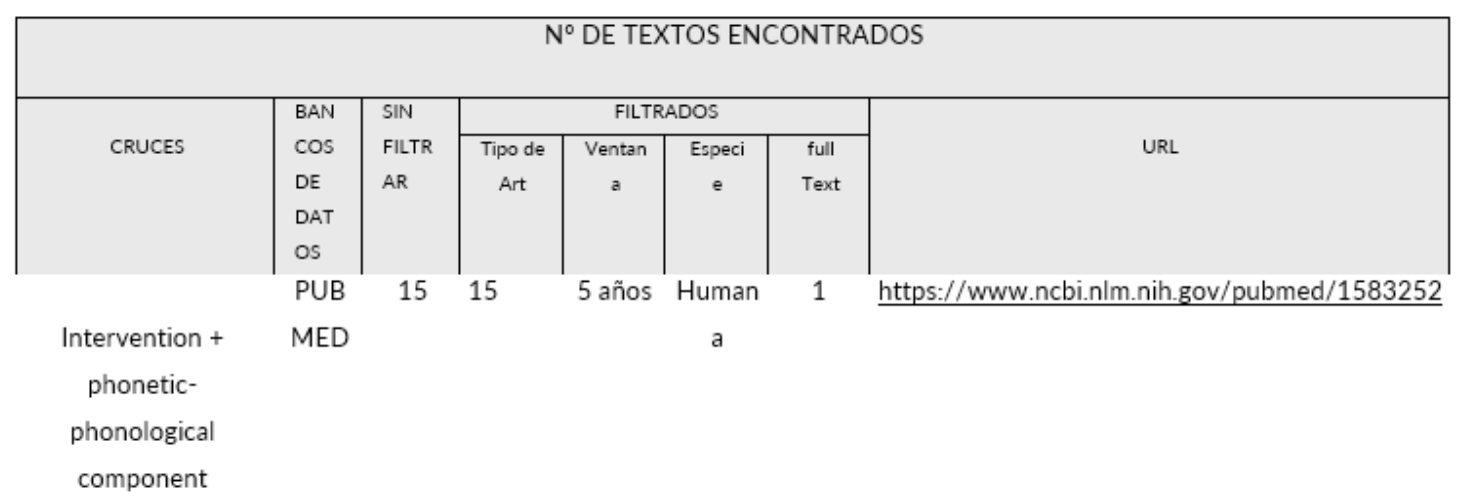

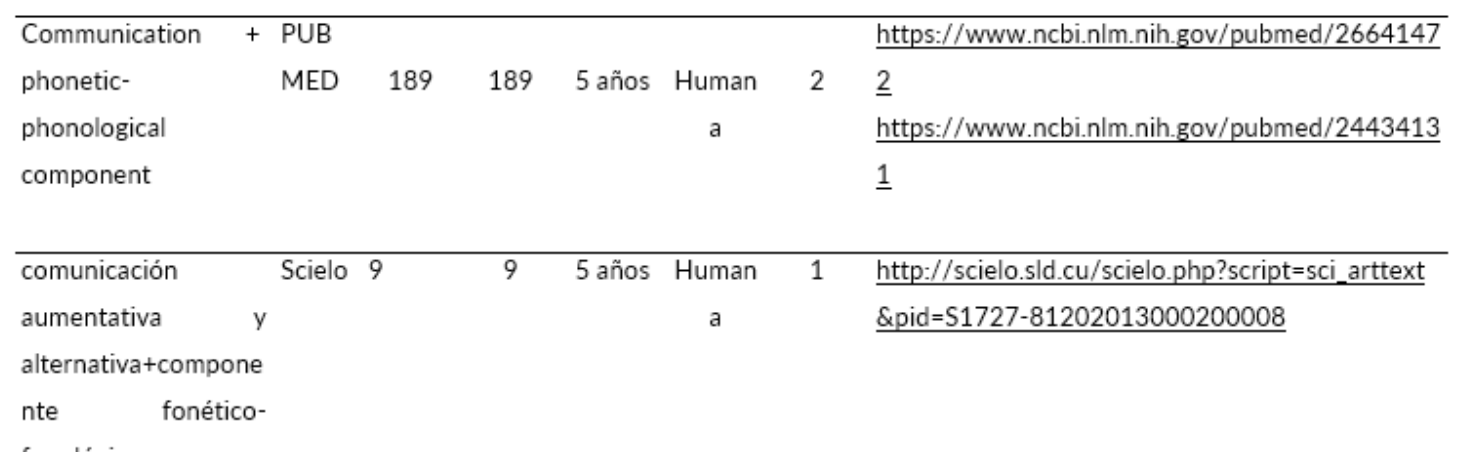


Tecnología de la comunicación y sistemas de comunicación en el lenguaje. Revisión sistemática desde la fonoaudiología.

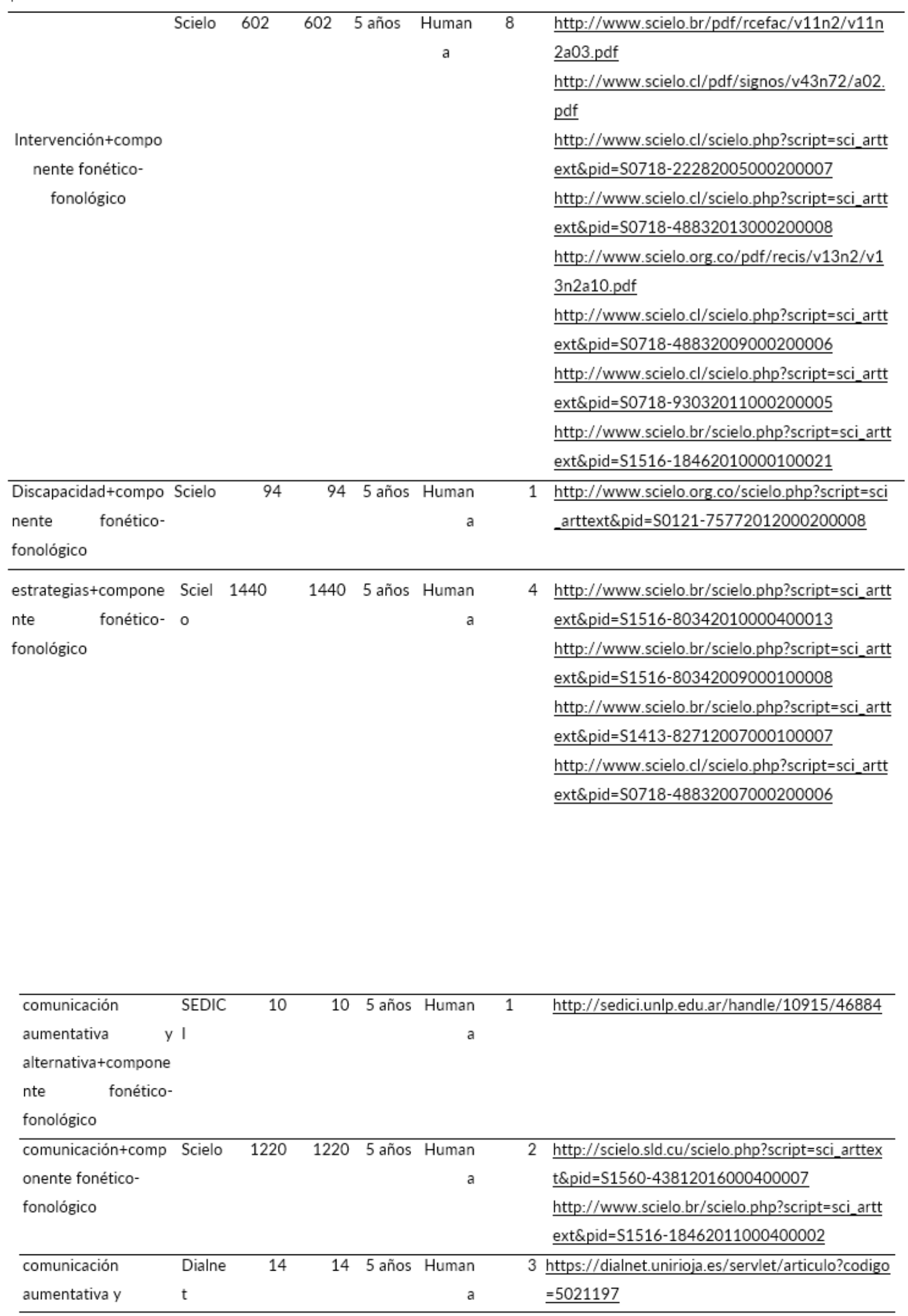


Pérez R Ginna V, Martínez M Aura J, Peñaloza M Zayda R, Ortega O Yury K, Sinuco M Yulieth, Zambrano Laura B, Martínez O Jennyfer A.

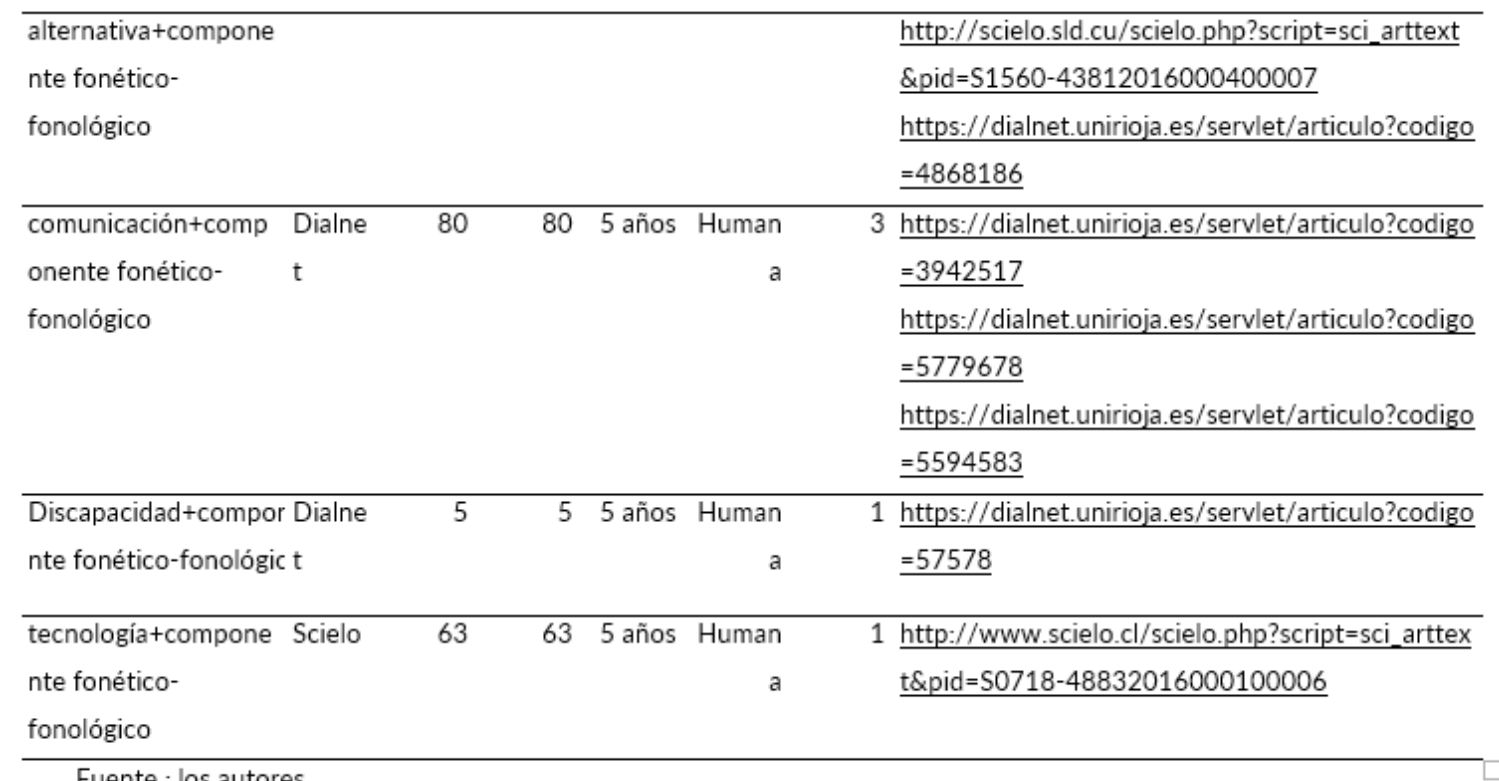

Fuente : los autores

Dentro de los resultados de la búsqueda exhaustiva de los artículos sobre el uso de los equipos de comunicación para personas con discapacidad en la bases de datos PUBMED, Scielo, Dialnet y Sedici en el componente Fonético Fonológico, se halla una cantidad explícita y formidable de artículos, posteriormente al efectuar la indagación de los estudios, de acuerdo a los cruces establecidos la información encontrada es muy insuficiente hallándose un total de 28 artículos que guardan gran relación con el tema investigativo distribuidos de la siguiente manera, en el primer cruce de intervención + componente fonético fonológico se encontraron 9 artículos los cuales equivalen al $32.1 \%$ de los cuales 2 artículos nos hablan que la intervención fonológica y Metafonológicas temprana puede promover la normalización del desarrollo del lenguaje y la adquisición normal de las habilidades de alfabetización para algunos niños con antecedentes de deterioro neurológico grave. Otro artículo nos menciona de las diversas perspectivas utilizadas para abordar el tema algunas se centran en la secuencia de aparición de fonemas y de los rasgos que los caracterizan (teorías conductistas y estructuralistas). Para lo cual aplica estrategias conocidas como procesos de simplificación fonológica (PSF). Dichas estrategias son operaciones mentales que constituyen un sistema innato. Otros 2 artículos nos hablan de cómo el modelo psicolingüístico ha influido de forma decisiva en la última década, la forma de diseñar, evaluar y confrontar la intervención en las dificultades del idioma. Esto es lo que ha demostrado ser muy útil en el campo de los trastornos del lenguaje, ya que trata de explicar cómo los seres humanos procesan la información que viene a sus sentidos, para acceder a las palabras almacenadas en su léxico y utilizar representaciones mentales que codifican la información en varios niveles.

Por lo tanto permite la comprensión de la naturaleza de los trastornos del lenguaje, siendo dos artículos los que mencionan cómo los niños adquieren el sistema fonológico-fonético de su lengua materna y describen la cronología de secuencia de adquisición del repertorio fonético-fonológico, otros tres artículos nos hablan desde el ámbito de la patología del lenguaje, el trastorno fonológico es frecuente y existe evidencia sobre la importancia del género, puesto que la cantidad de niños que presentan problemas es mayor que el número de niñas. No obstante, los déficits de estas últimas suelen ser más severos que los de los varones (Law, 1992). Por ello, es necesario considerar el género en el diagnóstico y en el tratamiento de los problemas del lenguaje. En el segundo cruce que se realizó sobre Comunicación + componente fonético-fonológico se encontró un total de 7 artículos que equivalen al 25\%, los cuales 1 artículo habla de la intervención con el uso de Sc@ut es un sistema de CAA, que ha sido efectiva para personas deficientes con graves problemas de comunicación. Tras el uso de Sc@ut, los usuarios han disminuido el número de con28 ductas disruptivas al bajar su nivel de ansiedad al tener un apoyo para comunicarse y organizar el 
tiempo. Además, ha mejorado la interacción con su grupo de iguales, sus profesores y familiares. En casos especiales, y gracias al refuerzo del sonido, ha mejorado el lenguaje oral y la estructuración de frases. Los otros 6 artículos nos hablan de la eficacia de un sistema alternativo de comunicación en parálisis Cerebral y el papel que juega la logopedia, cumpliendo con el principal objetivo de ayudar al desarrollo de la comunicación y del lenguaje cuando estas funciones se ven alteradas por causas sensoriales, físicas o psíquicas. Estos códigos junto con el nivel de expresión vocal o no-vocal que posea el usuario, le permiten comunicar y representar. En el tercer cruce que se realizó sobre comunicación aumentativa y alternativa + componente fonético-fonológico se encontró un total de 5 artículos los cuales equivalen al 17.8\%, siendo 2 de estos artículos, los que hablan de los sistemas de comunicación aumentativos y alternativos en personas con dificultad en los procesos de comunicación, y los otros 3 de la implementación de un programa de capacitación sobre estrategias de comunicación alternativa y aumentativa para la atención de niños con parálisis cerebral infantil y sobre el uso de los signos manuales de manera simultánea a la lengua oral para promover el desarrollo de la comunicación y el lenguaje en niños con o sin discapacidad.

En el cuarto cruce sobre discapacidad + componente fonético fonológico se encontró un total de 2 artículos que equivalen al $7.1 \%$ de los cuales los 2 artículos hablaban de cómo interpretar la estructura del lenguaje no verbal desde los niveles sintácticos, semántico y pragmático de la comunicación y los modelos de la misma para determinar la acción del gesto como signos en jóvenes en situación de discapacidad auditiva y el otro hablaba de cómo la aplicación integrada de la tecnología para el reconocimiento e interpretación de la lengua de señas colombianas, esta herramienta permite a los estudiantes aprender las señas básicas por medio de un glosario gráfico, en el quinto cruce de tecnología+componente fonético-fonológico se encontró un total de 1 artículo que equivale al 3.5\% del cual hablaba de la descripción fonetico- fonologica del sistema consonántico y como las nuevas tecnologías son cada vez más aprovechadas por el sector de la salud en las intervenciones terapéuticas y en el sexto cruce de estrategias + componente fonético fonológico se halló un total de 4 artículos que equivalen a $14.3 \%$ de los cuales hablan sobre la conciencia fonológica, que a su vez, es esencial para el desarrollo de la estrategia alfabético, ya que permite la segmentación de expresión a nivel del fonema, proceso fundamental para que la codificación se produzca.

En esta tabla se muestran los resultados que se evidenciaron después de la búsqueda realizada según la variable del componente semántico.

Tabla 6. Resultados de revisión Componente Semántico

\begin{tabular}{|c|c|c|c|c|c|c|c|}
\hline \multicolumn{8}{|c|}{$\mathrm{N}^{\circ}$ DE TEXTOS ENCONTRADOS } \\
\hline \multirow[b]{2}{*}{ CRUCES } & \multirow{2}{*}{$\begin{array}{l}\text { BANCOS } \\
\text { DE DATOS }\end{array}$} & \multirow{2}{*}{$\begin{array}{l}\text { SIN } \\
\text { FILTR } \\
\text { AR }\end{array}$} & \multicolumn{4}{|c|}{ FILTRADOS } & \multirow[b]{2}{*}{ URL } \\
\hline & & & $\begin{array}{l}\text { Tipo } \\
\text { de Art }\end{array}$ & $\begin{array}{c}\text { Ventan } \\
\text { a }\end{array}$ & $\begin{array}{c}\text { Especi } \\
e\end{array}$ & $\begin{array}{l}\text { full } \\
\text { Text }\end{array}$ & \\
\hline $\begin{array}{c}\text { semántica } \\
\text { +comunicación } \\
\text { alternativa }\end{array}$ & $\begin{array}{c}\text { Revista de } \\
\text { estudios e } \\
\text { investigaci } \\
\text { ón en } \\
\text { psicología } \\
\text { y } \\
\text { educación }\end{array}$ & 789 & 589 & 178 & 89 & 1 & $\frac{\text { http://revistas.udc.es/index.php/reiparticle/view }}{\underline{/ 642}}$ \\
\hline $\begin{array}{l}\text { semántica } \\
\text { +comunicación } \\
\text { alternativa }\end{array}$ & $\begin{array}{l}\text { Revista } \\
\text { Española } \\
\text { de } \\
\text { Discapaci } \\
\text { dad }\end{array}$ & 1 & 1 & 1 & 1 & 1 & $\begin{array}{l}\text { http://www.cedd.net/redis/index.php/redis/artic } \\
\text { le/view/84 }\end{array}$ \\
\hline comántirs & senire & 1007 & $1 \cap 74$ & $2 \cap 2$ & 10 & 1 & ht+n-//codiri unln odu ar/handla/1n015/520k5 \\
\hline
\end{tabular}

Rev. Signos Fónicos Vol 3 № 1 Abril / Septiembre 2017 
Pérez R Ginna V, Martínez M Aura J, Peñaloza M Zayda R, Ortega O Yury K, Sinuco M Yulieth, Zambrano Laura B, Martínez O Jennyfer A.

\begin{tabular}{|c|c|c|c|c|c|c|c|}
\hline $\begin{array}{l}\text { semántica } \\
\text { +comunicación } \\
\text { alternativa }\end{array}$ & SEDICE & 1927 & 1074 & 303 & 10 & 1 & http://sedici.unlp.edu.ar/handle/10915/53065 \\
\hline $\begin{array}{c}\text { semántica } \\
\text { +comunicación } \\
\text { alternativa }\end{array}$ & $\begin{array}{l}\text { ReiDoCre } \\
\text { a }\end{array}$ & 465 & 201 & 178 & 57 & 1 & http://digibug.ugr.es/handle/10481/21996 \\
\hline $\begin{array}{l}\text { semántica } \\
\text { +comunicación } \\
\text { alternativa }\end{array}$ & REVENE & 1 & 1 & 1 & 1 & 1 & $\begin{array}{l}\text { http://www.revistas.ucr.ac.cr/index.php/enfer } \\
\text { meria/article/view/3657 }\end{array}$ \\
\hline
\end{tabular}

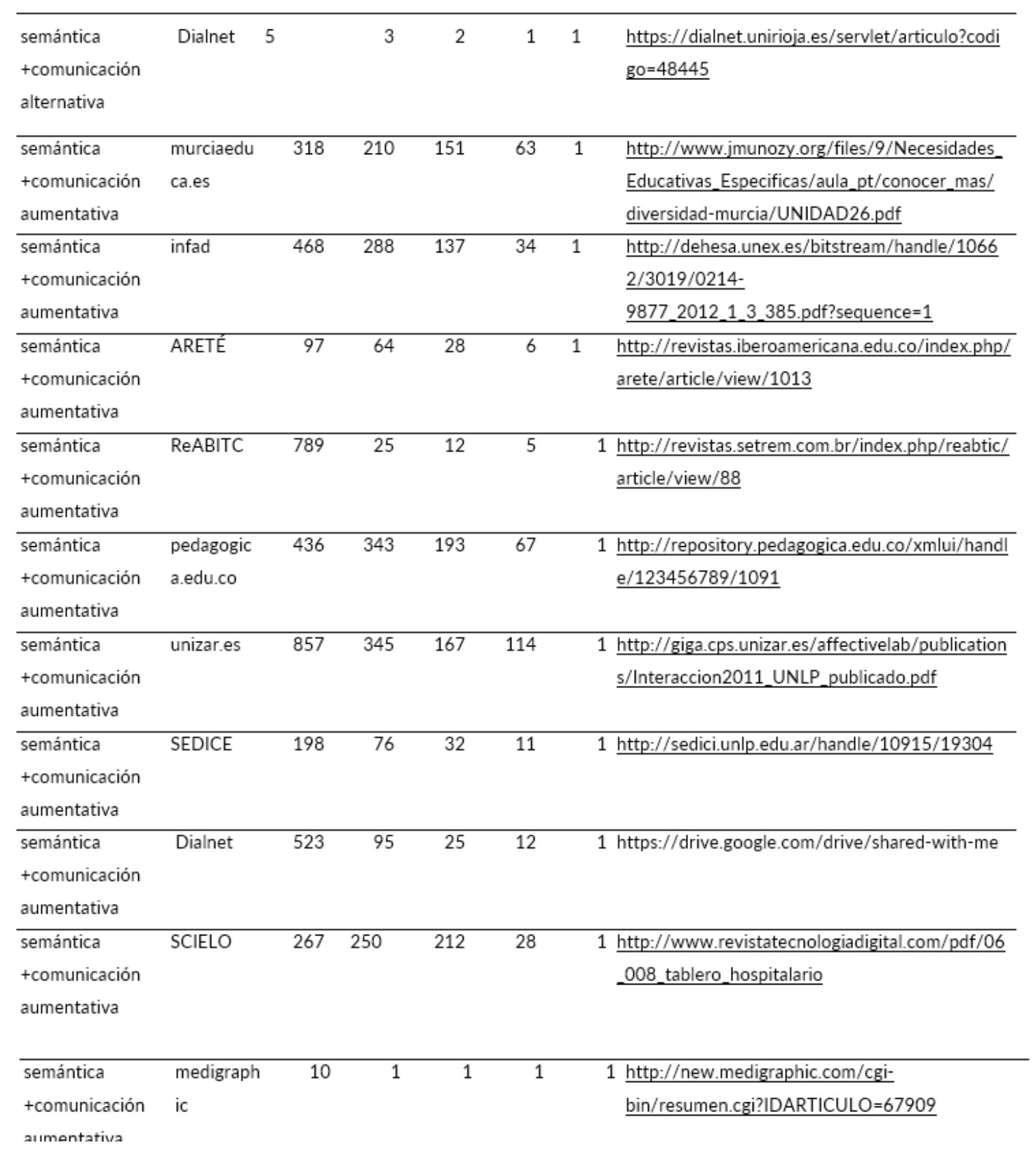


Tecnología de la comunicación y sistemas de comunicación en el lenguaje. Revisión sistemática desde la fonoaudiología.

\begin{tabular}{|c|c|c|c|c|c|c|}
\hline semántica & Dspace & 592 & 236 & 8 & 4 & 1 http://repositorio.espe.edu.ec/bitstream/21000/ \\
\hline $\begin{array}{l}\text { +comunicación } \\
\text { aumentativa }\end{array}$ & & & & & & 7400/1/AC-EAC-ESPE-047385.pdf \\
\hline \multirow[t]{3}{*}{$\begin{array}{l}\text { semántica + } \\
\text { comunicación }\end{array}$} & redalyc & 852 & 789 & 237 & 68 & 2 http://www.redalyc.org/pdf/447/44770212.pdf \\
\hline & & & & & & http://www.redalyc.org/pdf/3606/3606434220 \\
\hline & & & & & & 13.pdf \\
\hline
\end{tabular}

\begin{tabular}{|c|c|c|c|c|c|c|}
\hline $\begin{array}{l}\text { semántica + } \\
\text { comunicación }\end{array}$ & $\begin{array}{l}\text { diposit } \\
\text { digital de } \\
\text { document } \\
\text { s de la } \\
\text { UAB }\end{array}$ & 1.050 & 550 & 493 & 19 & 1 https://ddd.uab.cat/record/166504 \\
\hline $\begin{array}{l}\text { semántica + } \\
\text { comunicación }\end{array}$ & ARETÉ & 146 & 97 & 42 & 7 & $\begin{array}{l}1 \text { http://revistas.iberoamericana.edu.co/index.php } / \\
\text { arete/article/view/502 }\end{array}$ \\
\hline $\begin{array}{l}\text { semántica + } \\
\text { comunicación }\end{array}$ & $\begin{array}{l}\text { VISION } \\
\text { SY }\end{array}$ & 67 & 32 & 21 & 7 & $\begin{array}{l}1 \text { http://ojs.unimetro.edu.co/index.php/VisionSy/a } \\
\underline{\text { rticle/view/32 }}\end{array}$ \\
\hline $\begin{array}{l}\text { semántica + } \\
\text { comunicación }\end{array}$ & SCIELO & 512 & 280 & 195 & 55 & $\begin{array}{l}1 \\
\text { http://www.scielosp.org/pdf/rsap/v11n5/v11n5 } \\
\underline{\text { a16.pdf }}\end{array}$ \\
\hline $\begin{array}{l}\text { semántica + } \\
\text { comunicación }\end{array}$ & $\begin{array}{l}\text { Repositori } \\
\text { o Dspace }\end{array}$ & 12 & 6 & 4 & 2 & $\begin{array}{l}2 \text { http://repositorio.pedagogica.edu.co/xmlui/hand } \\
\underline{\text { le/123456789/737 }} \\
\underline{\text { http://www.repositoriocdpd.net:8080/bitstream }} \\
\text { /handle/123456789/363/Pon_KoonRA_Impacto } \\
\text { TecnologicoPersonas_2000.pdf?sequence=1 }\end{array}$ \\
\hline $\begin{array}{l}\text { semántica + } \\
\text { comunicación }\end{array}$ & Riberdis & 673 & 423 & 27 & 25 & 1 http://riberdis.cedd.net/handle/11181/4850 \\
\hline $\begin{array}{l}\text { semántica + } \\
\text { comunicación }\end{array}$ & $\begin{array}{l}\text { Repositoi } \\
\text { Universidi } \\
\text { ad de } \\
\text { Coruña }\end{array}$ & 44 & 1 & 1 & 1 & 1 http://ruc.udc.es/dspace/handle/2183/13214 \\
\hline $\begin{array}{l}\text { semántica + } \\
\text { comunicación }\end{array}$ & $\begin{array}{l}\text { Biblioteca } \\
\text { general } \\
\text { Andina }\end{array}$ & 36 & 32 & 16 & 15 & $\begin{array}{l}1 \text { http://www.comunidadandina.org/bda/docs/VE- } \\
\text { EDU-0003.pdf }\end{array}$ \\
\hline $\begin{array}{l}\text { semántica + } \\
\text { comunicación }\end{array}$ & PUBMED & 3006 & 2630 & 182 & 46 & $\begin{array}{c}1 \text { http://journals.plos.org/plosone/article/file?id=1 } \\
\underline{0.1371 / \text { journal.pone. } 0152773 \& \text { type=printable }}\end{array}$ \\
\hline
\end{tabular}


Pérez R Ginna V, Martínez M Aura J, Peñaloza M Zayda R, Ortega O Yury K, Sinuco M Yulieth, Zambrano Laura B, Martínez O Jennyfer A.

\begin{tabular}{|c|c|c|c|c|c|c|}
\hline semántica & SCIELO & 690 & 582 & 483 & 252 & $\begin{array}{l}9 \text { http://www.scielo.cl/scielo.php?script=sci_arttex } \\
\text { t\&pid=S0718-48832014000200009 } \\
\text { http://www.scielo.org.co/pdf/eia/n15/n15a06.p } \\
\text { df } \\
\text { http://scielo.isciii.es/scielo.php?script=sci_arttext } \\
\text { \&pid=S0212-97282015000300014 } \\
\text { http://www.scielo.cl/scielo.php?script=sci_arttex } \\
\text { t\&pid=S0718-09342009000100002 } \\
\text { http://www.scielo.cl/scielo.php?script } \\
\text { =sci_arttext\&pid=S0718-93032011000200007 } \\
\text { http://www.scielo.cl/pdf/estped/v38n1/art08.p } \\
\text { df } \\
\text { http://www.scielo.cl/scielo.php?script=sci_arttex } \\
\text { t\&pid=S0716-58112016000100014 } \\
\text { http://www.scielo.cl/pdf/rla/v46n1/art05.pdf } \\
\text { http://www.scielo.org.ve/scielo.php?script=sci_a } \\
\text { rttext\&pid=S1315-95182007000100005 }\end{array}$ \\
\hline semántica & $\begin{array}{l}\text { Revista de } \\
\text { neurologia }\end{array}$ & 451 & 387 & 136 & 3 & 1 https://www.neurologia.com/articulo/2009427 \\
\hline semántica & Dialnet & 78 & 87 & 34 & 26 & $\begin{array}{l}1 \text { https://drive.google.com/file/d/0B7uEnFN9h7Yt } \\
\underline{\text { TDBjaG9mdmVWY2M/view }}\end{array}$ \\
\hline semántica & $\underline{\mathrm{UNCP}}$ & 778 & 667 & 156 & 66 & $\begin{array}{l}1 \text { http://www.uncp.edu.pe/revistas/index.php/hori } \\
\text { zontedelaciencia/article/view/66 }\end{array}$ \\
\hline semántica & Sepln & 57 & 28 & 9 & 5 & $\begin{array}{l}1 \text { http://journal.sepln.org/sepln/ojs/ojs/index.php/ } \\
\text { pln/article/view/5358 }\end{array}$ \\
\hline semántica & & 723 & 524 & 252 & 64 & $\begin{array}{l}1 \text { https://drive.google.com/file/d/0B7uEnFN9h7Yt } \\
\text { TDBjaG9mdmVWY2M/view }\end{array}$ \\
\hline semántica & $\begin{array}{l}\text { psicothem } \\
\text { a }\end{array}$ & 4 & 1 & 1 & 1 & 1 http://www.psicothema.com/pdf/3794.pdf \\
\hline semántica & $\begin{array}{l}\text { Jóvenes } \\
\text { en la } \\
\text { ciencia }\end{array}$ & 1 & 1 & 1 & 1 & $\begin{array}{l}1 \text { http://www.jovenesenlaciencia.ugto.mx/index.p } \\
\underline{\text { hp/jovenesenlaciencia/article/view/1193 }}\end{array}$ \\
\hline
\end{tabular}

Fuente : los autores

Con relación a lo anterior se resalta que se encontraron 45 artículos que equivalen a un $100 \%$ de búsqueda, teniendo una variable dependiente la cual era equipos para la comunicación en personas con discapacidad y 4 variables independientes, utilizando 27 bases de datos donde se destacaron 3, que fueron en donde se encontró más artículos, las cuales son: Scielo, Dialnet y Dspace, realizando así el primer cruce el cual fue comunicación alternativa y semántica donde encontramos 6 artículos que fueron revisados, los cuales equivalen a un 13.3\%, 2 de ellos tratan el tema de personas con parálisis cerebral y especifican que es una de las causas más frecuentes discapacidad motora en niños, que si una persona no puede comunicarse no podrá tomar decisiones que afecten a su vida, en estos dos artículos el objetivo era la evaluación e intervención de la comunicación aumentativa y alternativa; en los 4 artículos restante nos habla que las personas deben desenvolverse en un contexto social para desarrollar la capacidad de comunicarse, las personas necesitan utilizar técnicas alternativas y aumentativas de comunicación como lo son los signos manuales. 
Seguidamente en el cruce de La comunicación aumentativa y semántica se encontró 11 artículos relacionados, de 11 bases de datos diferentes, los cuales equivalen a un $24.5 \%$, estos artículos nos hablan de las nuevas creaciones como dispositivos de comunicación para personas con discapacidad o niños que permitan mejorar la integración y desarrollar competencias para mejorar su necesidad de comunicación.

En el cruce de comunicación y semántica se encontró 12 artículos que fueron de gran utilidad, de 8 bases de datos, los cuales equivalen a un $26.7 \%$, los artículos me hablaban sobre las nuevas herramientas utilizadas para mejorar el componente semántico, como la realización de tableros, pictogramas, pautas en el momento de diagnosticar e intervenir los problemas de comunicación, y un desarrollo de competencias comunicacionales de alumnos con necesidades complejas de comunicación.

En la búsqueda de la palabra semántica, se obtuvieron 16 artículos que sirvieron para nuestra recopilación, de los cuales se utilizaron 8 bases de datos diferentes, estos 16 artículos equivalen al $35.5 \%$ de nuestra investigación, de estos artículos encontramos tres de los cuales nos habla de pacientes con parálisis cerebral donde se busca una solución diferente en uno encontramos la implementación de un sistema aumentativo para su desarrollo integral, en otro encontramos la intervención utilizando la tecnologías para la comunicación y el tercero que nos habla sobre las terapias de lenguaje oral y comunicación, encontramos más artículos relacionados con pacientes con síndrome de Williams y pacientes hospitalizados y de centros psiquiátricos, los 16 artículos tiene como fin la crear estrategias ya sean didácticas o de tecnologías que mejoren la calidad de vida de las personas.

La siguiente tabla muestra los resultados que se evidenciaron después de la búsqueda realizada según la búsqueda del componente sintáctico:

\section{Tabla 7. Resultados de revisión Componente Sintáctico}

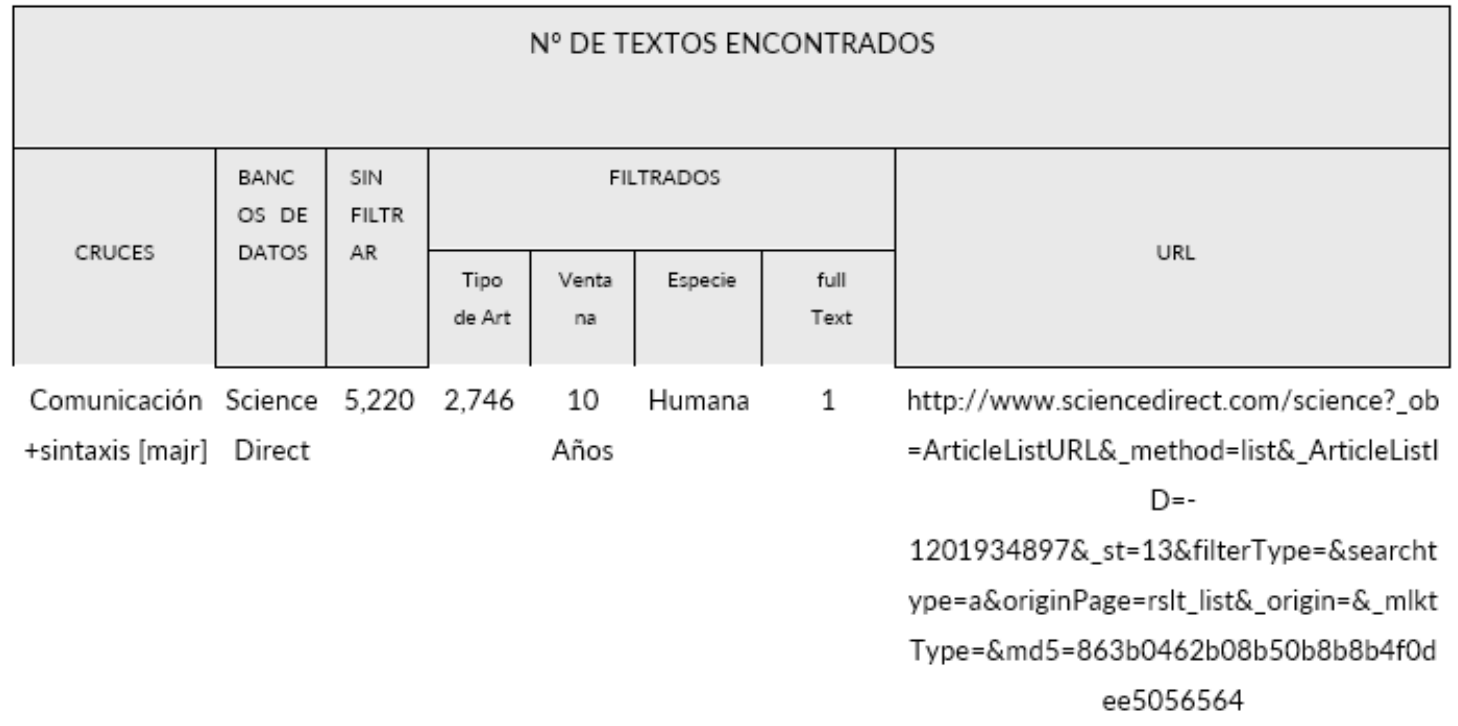

\begin{tabular}{|c|c|c|c|c|c|c|}
\hline $\begin{array}{l}\text { Comunicación Dialnet } \\
+ \text { sintaxis [majr] }\end{array}$ & 120 & 120 & $\begin{array}{c}10 \\
\text { años }\end{array}$ & Humana & 1 & $\begin{array}{l}\text { https://dialnet.unirioja.es/servlet/articulo?c } \\
\text { odigo }=5665307\end{array}$ \\
\hline $\begin{array}{l}\text { Comunicación scielo } \\
+ \text { sintaxis [majr] }\end{array}$ & 3030 & 3030 & $\begin{array}{c}10 \\
\text { años }\end{array}$ & Humana & 9 & $\begin{array}{l}\text { http://www.scielo.cl/result.html?cx=00277 } \\
8039995109192455 \% 3 \mathrm{Amjmfr} 2 \mathrm{dvt} 3 \mathrm{c} \& \text { cof } \\
\text { =FORID\%3A11\&q=Comunicaci\%C3\%B3n\% } \\
\text { 2Bsintaxis+\%5Bmajr\%5D+\&sa=Search\&site } \\
\text { url=www.scielo.cl\%2F\&ref=\&ss=1j1j2 }\end{array}$ \\
\hline
\end{tabular}


Pérez R Ginna V, Martínez M Aura J, Peñaloza M Zayda R, Ortega O Yury K, Sinuco M Yulieth, Zambrano Laura B, Martínez O Jennyfer A.

\begin{tabular}{|c|c|c|c|c|c|c|c|}
\hline $\begin{array}{c}\text { Tecnologia+sin } \\
\text { taxis [majr] }\end{array}$ & $\begin{array}{l}\text { Science } \\
\text { Direct }\end{array}$ & 3 & 3 & $\begin{array}{l}10 \\
\text { años }\end{array}$ & Humana & 0 & $\begin{array}{l}\text { http://www.sciencedirect.com/science? } \\
\text { ob=ArticleListURL\&_method=list\&_Articl } \\
\text { eListID=- } \\
1201937777 \& \text { _sort=r\&_st=13\&view=c\& } \\
\text { md5=19ddda4975fdd2c5ffb3c6c3ac25d } \\
4 e 2 \& \text { searchtype=a }\end{array}$ \\
\hline
\end{tabular}

\begin{tabular}{|c|c|c|c|c|c|c|}
\hline $\begin{array}{l}\text { Tecnologia+sin scielo } \\
\text { taxis [majr] }\end{array}$ & 1170 & 1170 & $\begin{array}{r}10 \\
\text { años }\end{array}$ & Humana & 0 & $\begin{array}{l}\text { http://www.scielo.cl/result.html?cx=002 } \\
\text { 778039995109192455\%3Amjmfr2dvt3c } \\
\text { \&cof=FORID\%3A11\&q=Tecnologia\%2Bsi } \\
\text { ntaxis+\%5Bmajr\%5D\&sa=Search\&siteurl= } \\
\text { www.scielo.cl\%2F\&ref=\&ss=48j2304j2 }\end{array}$ \\
\hline $\begin{array}{cl}\text { Tecnologia+sin } & \text { dialne } \\
\text { taxis [majr] } & \mathrm{t}\end{array}$ & 49 & 13 & $\begin{array}{r}10 \\
\text { años }\end{array}$ & Humana & 1 & $\begin{array}{l}\text { https://dialnet.unirioja.es/buscar/docume } \\
\text { ntos?querysDismax.DOCUMENTAL_TOD } \\
\text { O=Tecnologia\%20y\%20sintaxis\%20\&filtr } \\
\text { os.DOCUMENTAL_FACET_ENTIDAD=art } \\
\text { rev }\end{array}$ \\
\hline
\end{tabular}

\begin{tabular}{|c|c|c|c|c|c|c|c|}
\hline $\begin{array}{l}\text { Comunicación } \\
\text { aumentativa+si } \\
\text { ntaxis[majr] }\end{array}$ & $\begin{array}{l}\text { Scien } \\
\text { ce } \\
\text { direct }\end{array}$ & 175 & 118 & $\begin{array}{r}10 \\
\text { años }\end{array}$ & Humana & 1 & $\begin{array}{l}\text { http://www.sciencedirect.com/science?_ } \\
\text { ob=ArticleListURL\&_method=list\&_Articl } \\
\text { eListID=- } \\
\text { 1201939159\&_st=13\&filterType=\&searc } \\
\text { htype=a\&originPage=rslt_list\&_origin=\&_ } \\
\text { mlktType=\&md5=0e4dc7c7f4c8074eb40 } \\
\text { c259644ee0ced }\end{array}$ \\
\hline
\end{tabular}

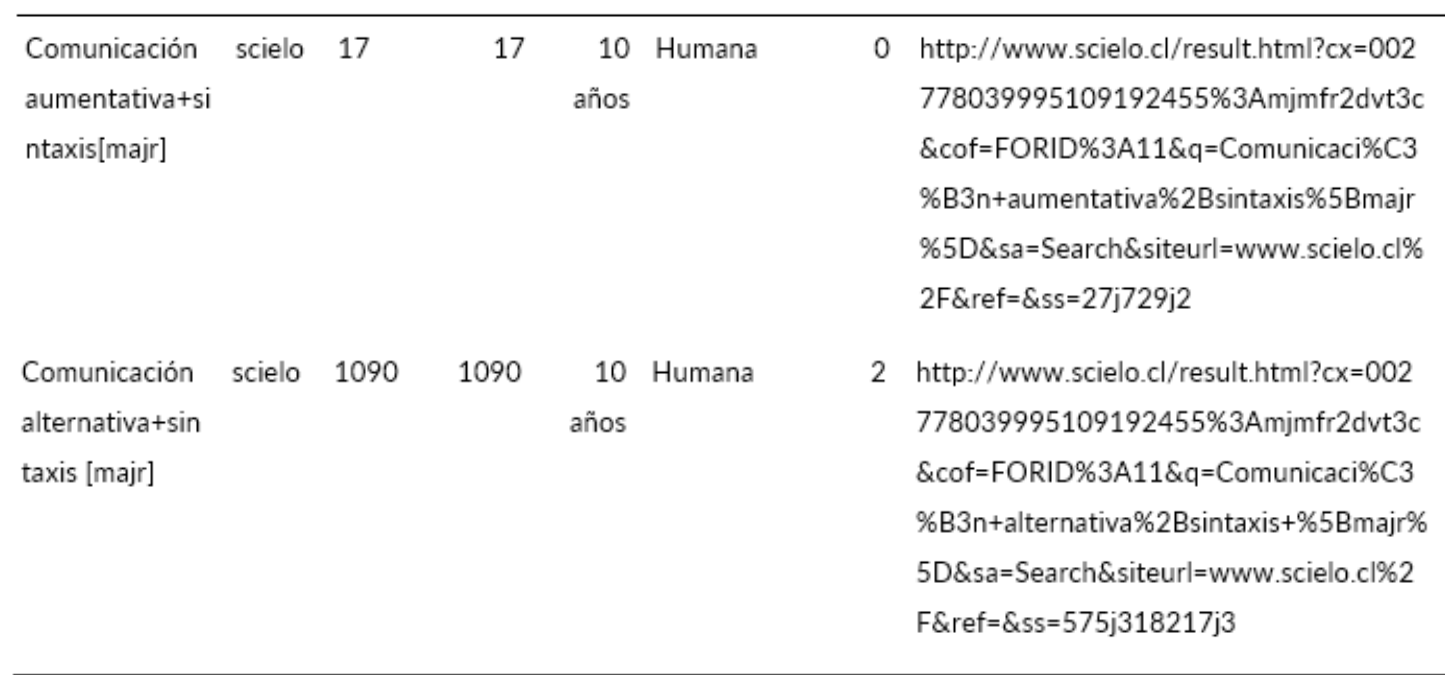

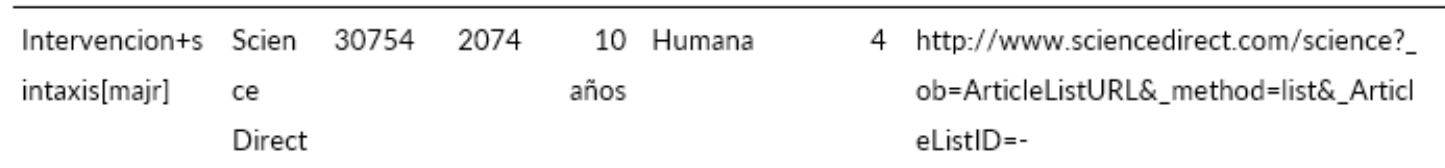

$1201943785 \&$ _st $=13 \&$ filterType $=\&$ searc htype $=a \&$ originPage $=$ rslt_list\&_origin $=\&_{\text {_ }}$ mlktType $=\& m d 5=4 f 9 c b 2 c 1 d 071$ ce09580 


\begin{tabular}{|c|c|c|c|c|c|c|c|}
\hline $\begin{array}{l}\text { Comunicación } \\
\text { alternativa+sin } \\
\text { taxis [majr] }\end{array}$ & scielo & 1090 & 1090 & $\begin{array}{r}10 \\
\text { años }\end{array}$ & Humana & 2 & $\begin{array}{l}\text { http://www.scielo.cl/result.html?cx=002 } \\
\text { 778039995109192455\%3Amjmfr2dvt3c } \\
\text { \&cof=FORID\%3A11\&q=Comunicaci\%C3 } \\
\text { \%B3n+alternativa\%2Bsintaxis+\%5Bmajr\% } \\
\text { 5D\&sa=Search\&siteurl=www.scielo.cl\%2 } \\
\text { F\&ref=\&ss=575j318217j3 }\end{array}$ \\
\hline $\begin{array}{l}\text { Intervencion+s } \\
\text { intaxis[majr] }\end{array}$ & $\begin{array}{l}\text { Scien } \\
\text { ce } \\
\text { Direct }\end{array}$ & 30754 & 2074 & $\begin{array}{r}10 \\
\text { años }\end{array}$ & Humana & 4 & $\begin{array}{l}\text { http://www.sciencedirect.com/science?_ } \\
\text { ob=ArticleListURL\&_method=list\&_Articl } \\
\text { eListID=- } \\
\text { 1201943785\&_st=13\&filterType=\&searc } \\
\text { htype=a\&originPage=rslt_list\&_origin }=\&_{-} \\
\text {mlktType=\&md5=4f9cb2c1d071ce09580 } \\
\text { fcdba2047daae }\end{array}$ \\
\hline $\begin{array}{l}\text { Intervencion+s } \\
\text { intaxis[majr] }\end{array}$ & Scielo & 1480 & 1480 & $\begin{array}{r}10 \\
\text { años }\end{array}$ & Humana & & $\begin{array}{l}\text { http://www.scielo.cl/result.html?cx=002 } \\
\text { 778039995109192455\%3Amjmfr2dvt3c } \\
\text { \&cof=FORID\%3A11\&q=Intervencion\%2B } \\
\text { sintaxis\%5Bmajr\%5D\&sa=Search\&siteurl } \\
\text { =www.scielo.cl\%2F\&ref=\&ss=773j55010 } \\
5 \mathrm{j} 3\end{array}$ \\
\hline
\end{tabular}

Como resultado de la búsqueda sistemática de artículos, fue posible extraer 21 artículos que se encontraban en estrecha relación con la investigación, el 50\% de estos artículos tenían en su contenido gran cantidad de información acerca de la comunicación aumentativa y alternativa y estrategias de intervención a través de la misma, otro 30\% tiene soporte teórico acerca de la morfosintaxis, el $20 \%$ restante de estos artículos tenía información teórica de las tecnologías de la comunicación.

Dentro del 30\% de artículos que hablaban de morfosintaxis fue posible identificar diferentes definiciones y sustentaciones acerca de la morfo-sintaxis, empezando por la descomposición del término, siendo indispensable empezar por definir tanto el término "morfema" como el "sintagma, que corresponde a la palabra o grupo de palabras que constituyen una unidad sintáctica y que cumplen una función determinada con respecto a otras palabras de la oración.7 Dichos artículos arrojaron información referente a las características de la morfosintaxis como por ejemplo que este es el componente encargado de agrupar cada una de las palabras realizando estructuraciones gramaticales según su función, de esta manera es posible realizar una clasificación: en donde unas palabras tendrán un significado léxico como los sustantivos, los adjetivos y los verbos, mientras que otras tendrán una categoría gramatical, entre ellas encontramos los adverbios, las preposiciones, los artículos, conjunciones y pronombres. Siendo posible brindarle al hablante una expresión completa y clara de lo que quiere manifestar, acompañado de otras características como la entonación y la prosodia.8 9

Con el fin de poder intervenir de manera íntegra este componente fue de gran ayuda encontrar estrategias que orientan a resultados positivos en corto tiempo, y además son llamativos para el niño, en el 50\% de los artículos encontrados, se hizo el hallazgo del uso de sistemas de los sistemas alternativos y aumentativos de comunicación (SAAC) puesto que son instrumentos lingüísticos que permiten la comunicación en personas con problemas para hacerlo oralmente. Constituyen una de las herramientas de intervención más importantes en el ámbito fonoaudiológico, dichos sistemas son uno de los recursos más potentes y utilizados en el arsenal profesional del Fonoaudiólogo.10 
Pérez R Ginna V, Martínez M Aura J, Peñaloza M Zayda R, Ortega O Yury K, Sinuco M Yulieth, Zambrano Laura B, Martínez O Jennyfer A.

Debido a la importancia de estos sistemas en el momento de la intervención, resulta importante nombrar los tipos de sistemas aumentativos y alternativos hallados en la búsqueda, entre los cuales encontramos:

-SPC (Sistema Pictográfico de Comunicación), Minspeak, Arasaac, BLISS, PECS, Tableros de comunicación no electrónicos, Tableros de comunicación en soporte informático, Comunicadores.11 Por otro lado, en los artículos se lograron encontrar estrategias de intervención que incorporaron el uso de las TIC en el momento de la intervención, algunas de dichas estrategias que apoyan específicamente el componente morfosintáctico son:

-BEN, EDILIM, CLIC y SENSwitcher12

El 10\% de los artículos hallados permitió llegar al descubrimiento de herramientas que mezclan los sistemas de comunicación aumentativa y alternativa y las TIC, entre ellos podemos encontrar: -Barrido, Webcam, Teclado en pantalla12

La siguiente tabla muestra los resultados que se evidenciaron después de la búsqueda realizada según el cruce de variables de Equipos de comunicación para personas con discapacidad:

Tabla 8. Resultados de revisión Equipos de comunicación para personas con discapacidad

\begin{tabular}{|c|c|c|c|c|c|c|c|}
\hline \multicolumn{8}{|c|}{$\mathrm{N}^{\circ}$ DE TEXTOS ENCONTRADOS } \\
\hline \multirow[b]{2}{*}{ CRUCES } & \multirow{2}{*}{$\begin{array}{l}\text { BANCOS } \\
\text { DE } \\
\text { DATOS }\end{array}$} & \multirow{2}{*}{$\begin{array}{l}\text { SIN } \\
\text { FILTR } \\
\text { AR }\end{array}$} & \multicolumn{4}{|c|}{ FILTRADOS } & \multirow[b]{2}{*}{ URL } \\
\hline & & & $\begin{array}{l}\text { Tipo } \\
\text { de Art }\end{array}$ & $\begin{array}{c}\text { Ventan } \\
\text { a }\end{array}$ & $\begin{array}{c}\text { Especi } \\
e\end{array}$ & $\begin{array}{l}\text { full } \\
\text { Text }\end{array}$ & \\
\hline
\end{tabular}

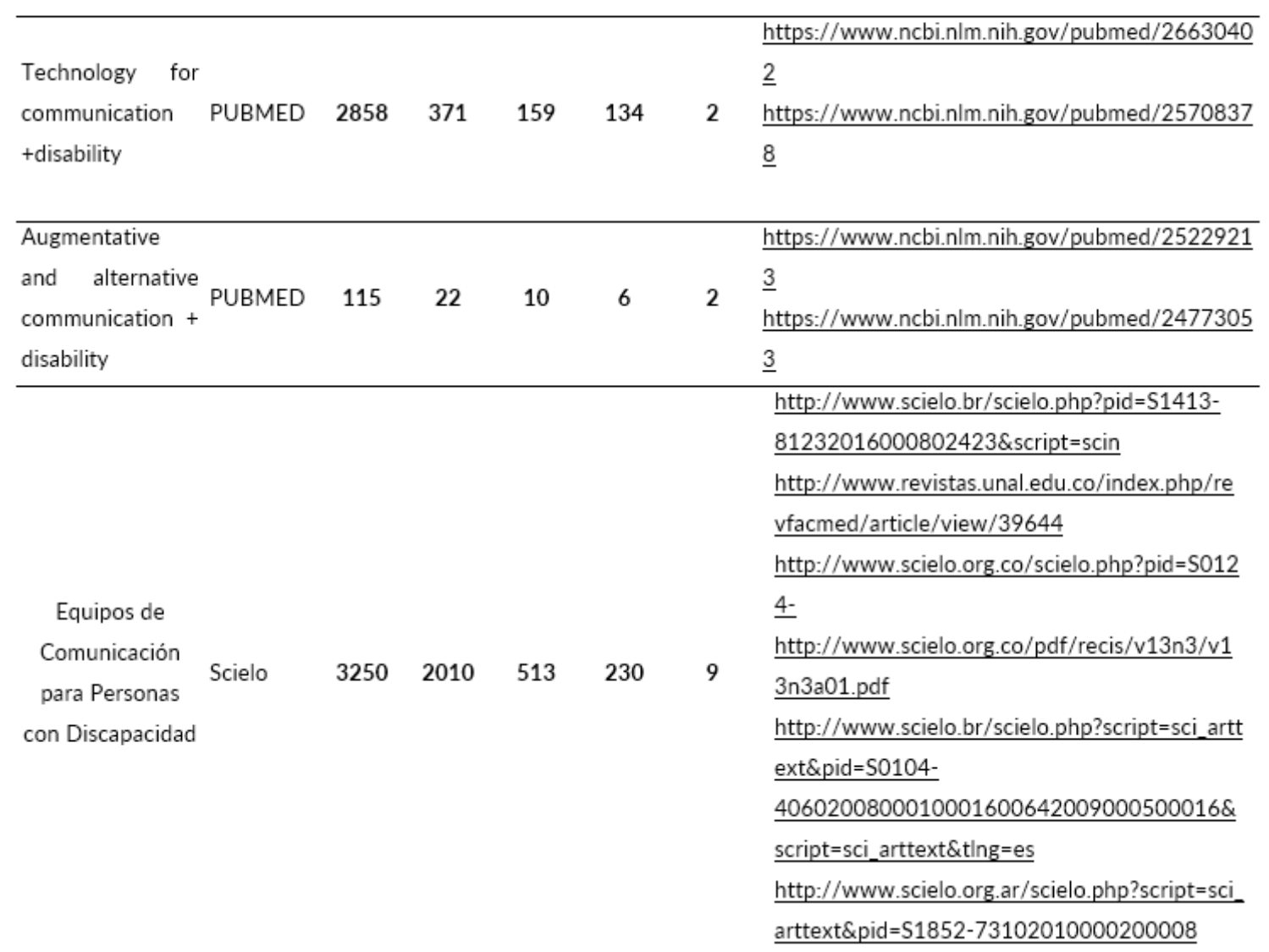


Tecnología de la comunicación y sistemas de comunicación en el lenguaje. Revisión sistemática desde la fonoaudiología.

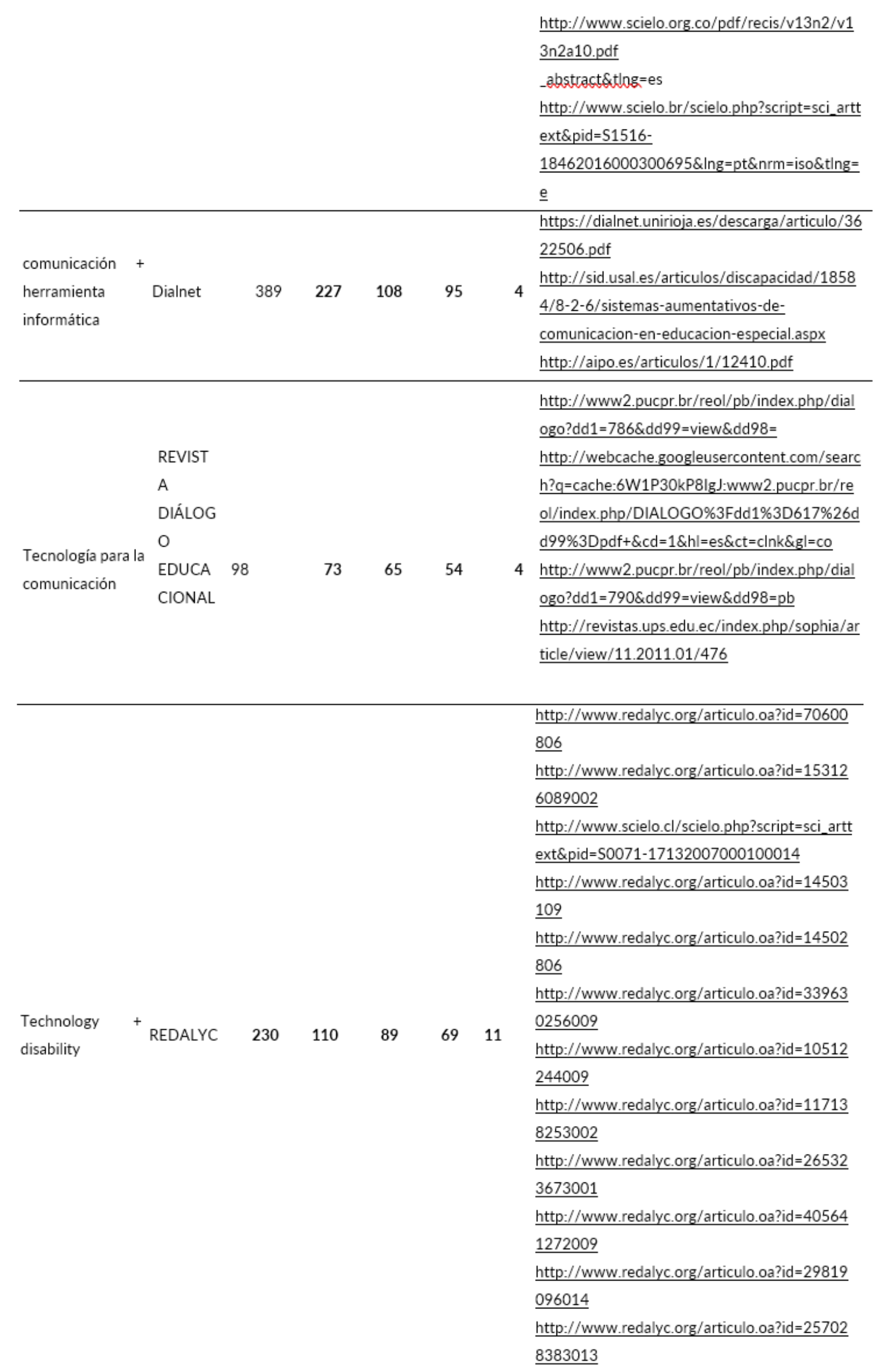


Pérez R Ginna V, Martínez M Aura J, Peñaloza M Zayda R, Ortega O Yury K, Sinuco M Yulieth, Zambrano Laura B, Martínez O Jennyfer A.

\begin{tabular}{|c|c|c|c|c|c|c|}
\hline $\begin{array}{l}\text { Communication } \\
\text { strategies with } \\
\text { technology }\end{array}$ & $\begin{array}{l}\text { LINHAS } \\
\text { CRÍTICAS }\end{array}$ & 31 & 27 & 15 & 10 & $1 \frac{\text { http://periodicos.unb.br/index.php/linhascritic }}{\underline{\text { as/article/view/5347 }}}$ \\
\hline $\begin{array}{l}\text { Augmentative } \\
\text { and alternative } \\
\text { communication + } \\
\text { disability + } \\
\text { strategies }\end{array}$ & EDUTEC & 55 & 43 & 32 & 27 & $\begin{array}{l}1 \frac{\text { http://www.edutec.es/revista/index.php/edutec }}{\text {-e/article/view/194 }} \\
\end{array}$ \\
\hline $\begin{array}{l}\text { Augmentative } \\
\text { and alternative } \\
\text { communication + } \\
\text { disability + } \\
\text { strategies }\end{array}$ & $\begin{array}{l}\text { REPOSIT } \\
\text { ORIO } \\
\text { PEDAGÓ } \\
\text { GICO }\end{array}$ & 45 & 35 & 29 & 11 & $\begin{array}{l}1 \underline{\text { http://repositorio.pedagogica.edu.co/xmlui/bitstr }} \\
\underline{\text { eam/handle/123456789/737/TO- }}\end{array}$ \\
\hline
\end{tabular}

Fuente: los autores

Partiendo de la evidencia que genera una descripción acerca del uso de la Equipos de Comunicación para Personas con Discapacidad según los criterios establecidos como palabras claves, se encontró un número de estudios, en una determinada bases de datos, las cuales fueron; Pubmed, Scielo, Dialnet; Revista Diálogo Educacional, Redalyc, Linhas Críticas, Edutec, Repositorio Pedagógico.

De acuerdo a los hallazgos de la búsqueda en las diferentes bases de datos mencionadas anteriormente, se encontró que los artículos arrojados en su gran mayoría hacen referencia a otras claves relacionadas, tales como; patologías referidas con dificultades en el cerebro, patologías de origen médico, como: diabetes, hipertensión, entre otras. Luego se realizaron los diferentes filtros hasta tener el texto completo referentes al tema, arrojando como resultado 35 informes que conllevan conceptualizaciones pertinentes y relacionadas al tema planteado (tecnologías para la comunicación para personas con discapacidad), durante el proceso, se evidenció del total de la búsqueda que un $99,51 \%$ no está relacionado con el tema principal referente al uso de los equipos de comunicación para personas con discapacidad, Un $0,49 \%$ que fue indagado, se vio relacionado con el uso de los equipos de comunicación para personas con discapacidad, de este, se relacionan temas tales como; el razonamiento lógico de las tecnologías de información, uso de las tecnologías de información para el aprendizaje; herramientas de software libres para la comunicación con discapacidad.

El proceso marca evidencia de 35 artículos mencionados anteriormente, los cuales equivalen a un $100 \%$ referente al uso de los equipos de comunicación para personas con discapacidad, de los cuales un 2,8\% menciona que; el concepto de "desorden de comunicación" se entiende, como toda limitación en la interacción comunicativa que puede traer como consecuencia una restricción en la participación de los roles y funciones que individuos o grupos tienen en la cultura y en la sociedad, y que involucran deficiencias en las capacidades y potencialidades del individuo para comunicar. Un 5,71\% refiere, que las personas con discapacidad, presentan, impedimentos para desarrollar habilidades comunicativas y lingüísticas, lo cual proporciona una restricción hacia la exploración e interacción con el entorno, la gente, la expresión de emociones, necesidades, pensamientos y el intercambio de información. Un 31, 4\% tratan de la influencia de la tecnología para la comunicación y el aprendizaje. Un 22,8\% describen la importancia de un sistema aumentativo y alternativo como medio de apoyo para las personas con discapacidad. Un 8,5\% explican la importancia de herramientas de software libre que pueden apoyar las intervenciones y herramientas que facilitan la accesibilidad al computador. Un 2,8\% analiza los métodos de uso de la informática educativa para el desarrollo el razonamiento lógico de los estudiantes, utilizando las teorías de Piaget y Secuencia Fedathi Cread presentando formas de utilizar las computadoras, los tipos de aplicaciones y software. Un 25,7\% Enfatiza principalmente en el uso de los equipos de comunicación para personas con discapacidad. 
Tecnología de la comunicación y sistemas de comunicación en el lenguaje. Revisión sistemática desde la fonoaudiología.

\section{ANÁLISIS Y DISCUSIÓN}

Es muy bien sabido que el medio sociocultural para el ser humano juega un papel primordial en el desarrollo de la comunicación y el lenguaje, tal adquisición no sería posible sin un soporte material que facilite y enmarque la capacidad de reflexionar sobre la estructura fonológica de la lengua oral. Es así como la fonética se ocupa de las características físicas de los sonidos: los rasgos laríngeos, el punto y el modo de articulación y la fonología estudia la manera en que se organiza el sistema de sonidos que conforman el lenguaje. En esta adquisición existe un orden de aparición y unas estructuras de desarrollo muy definidas; la rapidez de adquisición varía de unos niños a otros (Monfort M, Juárez Sánchez A). Por tal razón hablantes del portugués en Brasil dominan un punto y modo articulatorio diferente al español debido a que distinguen la / $/$ / de la /b/ fonéticamente, al contrario del español, en el que tanto la / $/$ como la /b/ constituyen un fonema bilabial sonoro (con un alófono fricativo en posición intervocálica) mientras que en portugués la /b/ es una bilabial sonora y la / $/$ / es una labiodental sonora. A los brasileños les cuesta no hacer esta distinción. Es evidente entonces que el desarrollo del sistema fonológico durante el proceso de adquisición se produce poco a poco, y la mayoría de los niños tienen como resultado de la maduración de este conocimiento un sistema consistente con la entrada recibida del grupo social en el que opera. En este periodo es posible que el niño sabe más que lo que las partes puedan entender, porque no siempre se manifiesta todo el conocimiento y toda la capacidad de producción de los sonidos.13 Con base a lo anterior se habla de un proceso de aprendizaje sintético que se concentra en el conocimiento y comprensión de las partes (fonemas) para su posterior inclusión en el todo discurso (Ysunza A, Pamplona M). Algunos autores refieren que el tratamiento enfocado sólo en el aspecto articulatorio del lenguaje resulta insuficiente para el mejoramiento de las habilidades comunicativas del paciente, puesto que debe considerarse no sólo el aprendizaje de cómo producir fonemas e integrarlos en palabras, sino también la capacidad para integrar estas palabras en frases con un fin comunicativo.14

Por lo tanto desde la perspectiva del enfoque Fonético- Fonológico es evidente que los equipos de comunicación Aumentativa y Alternativa para personas con discapacidad han permitido demostrar que las personas que presentan estos tipos de inhabilidades como déficit auditivo parálisis cerebral, parálisis cerebral infantil, parálisis cerebral espástica, discapacidad intelectual y del desarrollo, trastornos del espectro autista, trastorno específico del lenguaje, síndrome de Down entre otros, generalmente presentan un gran rango de dificultad en la comunicación hecho que limita la interacción y la forma de relacionarse con personas de su entorno social, escolar, sociocultural y entorno familiar. Debido a que no se hace evidente el uso correcto de un signo o código que permita generar una intención comunicativa donde el emisor pueda emitir ideas, deseos y sentimiento y de esta manera se produzca el mensaje en el acto de la comunicación. Desde el plano funcional se reconoce la discapacidad como "un término genérico que engloba deficiencias, limitaciones de la actividad y restricciones de la participación. "La Clasificación Internacional de la Discapacidad y el Funcionamiento (CIF) denota los aspectos de la interacción entre las personas con un problema de salud y factores personales y ambientales; el análisis de la CIF nos orienta hacia la propuesta de un modelo que tome como referencia los componentes de funcionamiento, condición de salud y discapacidades del enfoque de interacción de la persona con el entorno, desde una perspectiva multifactorial".15 Lo cual denota que la comunicación es una necesidad inherente a todo ser humano, según argumenta Campabadal (2005) se encuentra presente en todo momento, es decir, una persona no puede dejar de comunicarse. Lo anterior es debido a que la comunicación se concibe según Caro (sistema fonético) como: "...el proceso mediante el cual unos seres hacen partícipes a otros de aquello que hacen, tienen, sienten o piensan, mediante una determinada actividad, que supone un intercambio de información, produciendo cambios en el entorno. La comunicación se produce cuando un individuo (emisor) realiza algo para que, a través de la interacción, se produzca un conocimiento de lo que pretende, en otra persona (receptor).15 Así mismo Von Tetzchner et al. (1993), define los sistemas AAC como herramientas que ayudan a amplificar o apoyar la expresión o la comprensión del lenguaje oral, de manera temporal o permanente. Dentro del abanico de sistemas de AAC, existen sistemas sin ayuda (gestos naturales, signos manuales, lenguas de signos, alfabeto dactilológico) o sistemas con ayuda (pictogramas, comunicadores con imágenes, comunicadores electrónicos de voz).16 
Pérez R Ginna V, Martínez M Aura J, Peñaloza M Zayda R, Ortega O Yury K, Sinuco M Yulieth, Zambrano Laura B, Martínez O Jennyfer A.

En esta revisión sistemática se pudo observar a grandes rasgos los aportes que nos brinda el uso de las herramientas de software libre, Prelingua y Globus 3, desempeñando cada uno una función diferente e importante según sea la necesidad del individuo, por tanto, el software libre como su nombre lo indica respeta la libertad de los usuarios y la comunidad. A grandes rasgos, significa que los usuarios tienen la libertad de ejecutar, copiar, distribuir, estudiar, modificar y mejorar el software. Es decir, el «software libre» es una cuestión de libertad, no de precio. Para entender el concepto, piense en «libre» como en «libre expresión». Decimos «libre software», empleando ese adjetivo francés o español, derivado de «libertad», para mostrar que no queremos decir que el software es gratuito. El software libre representa en muchos contextos una filosofía de trabajo y una alternativa de vida en donde el trabajo compartido de algunos se convierte en un beneficio para todos. Asimismo, la Prelingua que nació en el Grupo de Tecnologías de las Comunicaciones de la Universidad de Zaragoza, bajo el proyecto "Comunica". Prelingua trabaja aspectos como conciencia fonológica, intensidad de la voz, soplo, duración de sonidos, tonalidad y articulación de vocales y Globus 3 que es otra herramienta está pensada para personas con discapacidad auditiva y fue desarrollada por Jordi Lagares. Con esta técnica o sistema los usuarios pueden ver que han emitido sonidos por medio de gráficos. Ante la detección de sonidos, el programa responde gráficamente con figuras geométricas y colores, estas herramientas están diseñadas desde el componente fonético fonológico para población con déficit auditivo y desórdenes de la comunicación humana.

Después de realizar esta búsqueda de artículos se pueden observar los grandes aportes que las tecnologías han realizado a las personas con discapacidad y a niños que están adquiriendo su proceso de aprendizaje. Se observa que los avances tecnológicos son de gran utilidad para mejorar las dificultades de las personas, dando a conocer los problemas que surgen en personas con alguna alteración en su comunicación, como lo es la alteración en el componente semántico por tal motivo se han realizado estrategias que ayuden a mejorar esta problemática, como la utilización de estrategias didácticas y tecnológicas. Es así, que se debe tener claro que "La semántica estudia la relación entre los gráficos y el significado que se encuentra implícito de acuerdo con la función que realiza. Aplica el término a todos los signos y símbolos que son portadores de un mensaje, siendo estos un motivo gráfico que puede ser homológico con significado abstracto, como formas irreales de la interpretación humana o analógico con significado lógico, directo o denotativo. Los pictogramas, por su parte tienen un motivo analógico ya que buscan representar el objeto sin posibilidades de interpretaciones que nos lleven a la polisemia. En el mismo sentido en el nivel de la semántica hay 3 definiciones que no se nos deben escapar y que nos ayudan a la formulación de los pictogramas: el significante que es cualquier gráfico que porta un mensaje, en este caso los pictogramas; el significado que es el mensaje en sí que contiene el significante y la función que sencillamente es el objetivo por el cual fue diseñado el significante. Para diseñar un correcto significante la forma más correcta sería elaborarlos de manera creativa, pero cumpliendo con los estándares y las normas convencionales vigentes existentes para no aburrir al receptor o hacer inentendible el significante con conceptos muy abstractos." (De la Torre G.)17 Por tanto, se utiliza la comunicación aumentativa y alternativa al desarrollar programas computacionales destinados a apoyar el análisis psicolingüístico de los términos elicitados mediante encuestas de léxico disponible. Utilizando un algoritmo basado fundamentalmente en las relaciones de secuencia de las palabras disponibles, uno de los programas que se utilizó fue un DispoGrafo, el cual ingresa los términos elicitados y genera luego automáticamente grafos los cuales representan palabras y cuyas aristas simbolizan las relaciones entre ellas; los grafos se interpretan como redes semánticas cuya configuración expresa las relaciones semánticas subyacentes en el corpus. Por otra parte el diseño de guías metodológicas de pictogramas e ideogramas afina los sistemas de comunicación alternativos, utilizados en el área de Terapia de Lenguaje en instituciones de educación especial por medio de la creación de herramientas educativas para orientar el desarrollo de competencias comunicacionales de alumnos con necesidades complejas de comunicación por medio de sistemas aumentativos y alternativos, los cuales "Son instrumentos de intervención logopédica/educativa destinados a personas con alteraciones diversas de la comunicación y/o el lenguaje, y cuyo objetivo es la enseñanza mediante procedimientos específicos de instrucción, de un conjunto estructurado de códigos no vocales que permiten funciones de representación y sirven para llevar a cabo actos de comunicación funcional, espontánea y generalizable por sí solos o en conjunción

40 con otros códigos, vocales o no vocales." (Tamarit).18

Rev. Signos Fónicos Vol $3 \mathrm{~N}^{\circ} 1$

Abril / Septiembre 2017 
Cuando hablamos de una alteración de semántica y comunicación nos hacemos un enfoque en el déficit cognitivo, el cual abarca gran escala de nuestra investigación debido a que es el déficit más encontrado en nuestra revisión.

Por otra parte, para poder crear un sistema de comunicación es necesario conocer las necesidades del usuario, por ende el primer paso consiste en evaluar al usuario, conocer sus habilidades y limitaciones, realizando una comparación entre el entorno físico y social en el que se desenvuelve el usuario, y como hace uso del proceso comunicativo. Puesto que la adquisición de las habilidades comunicativas se llevan a cabo por ciclos, en donde al principio vemos que se expresa haciendo uso del proceso de anticipación, el cual será básico para alcanzar una verdadera intención comunicativa.19

Cuando esa intención comunicativa se ve inhibida por alteraciones cognitivas una buena estrategia es el uso de la comunicación aumentativa y alternativa puesto que es una opción que facilita la ejecución de ciertos procesos como; abstracción, conceptualización, y representación del mundo según las vivencias de cada ser humano en especial aquellos que posean necesidades especiales. 2021

Pero, ¿porque es necesario que todos los seres nos comuniquemos?, es tan similar a la importancia de la respiración respecto a la supervivencia, pues sin comunicación no se alcanzara el objetivo de cada persona; llegar a ser seres sociales. 2223

Que una persona posea limitaciones en producción o comprensión del habla no significa que no tenga las mismas necesidades comunicativas que quien no posee dichas limitaciones, por ello es indiscutible que se le debe proporcionar un sistema que le permita dar solución a cada una de esas necesidades, sin importar si es haciendo uso del habla o de otras estrategias, el principal objetivo será llegar a cumplir con la misma función del habla: expresarse.

Dentro de la búsqueda de estrategias de intervención se hizo un estudio detallado de cada una de ellas, y una selección de cuáles de estas herramientas eran útiles para llegar a intervenir en las alteraciones del lenguaje, específicamente en el componente morfosintáctico, y cuáles no lo eran. Dando como resultado las siguientes herramientas:

- SPC (Sistema Pictográfico de Comunicación):Es el sistema más utilizado en nuestro contexto, principalmente por su facilidad de interpretación, dado que sus iconos representan de forma clara la idea que el usuario desea transmitir, esta estrategia brinda ayuda a aquellas personas con alteraciones cognitivas severas que dan como resultado alteraciones en el lenguaje hablado, personas sin acceso a la lecto - escritura, y en general es de fácil acceso para todos aquellos seres humanos que presenten problemas en su comunicación, esta estrategia se introdujo en las de intervención en el componente morfosintáctico debido a que mediante el uso de símbolos e iconos el usuario podrá estructurar oraciones de simples a complejas con el uso de sus distintas categorías, las cuales son: personas, verbos, descriptivos, nombres, artículos, conjunciones, preposiciones, conceptos de tiempo, alfabeto, colores, numeros, simbolos que representan palabras de uso social como el saludo, las disculpas, las gracias entre muchas otras. el uso de esta herramienta de intervención se puede incorporar a otros materiales, como por ejemplo un tablero de comunicación que haga uso del SPC, o incluso un software que también use este mismo método.20 23

- ARASAAC: Es un portal que ofrece pictogramas para la comunicación aumentativa y alternativa y dispone de cinco catálogos: pictogramas en color, pictogramas en blanco y negro, fotografías, videos y fotografías en color en lengua de signos española. Los más de 17500 pictogramas con que cuenta la página son de libre acceso y uso y están traducidos a más siete idiomas. La página cuenta también con herramientas en línea como creadores de animaciones, símbolos y frases, lo cual es de gran utilidad para los usuarios, pues no solo se pueden usar los símbolos ya existentes, sino que se pueden crear unos nuevos, orientados a las necesidades de los usuarios, que en este caso serían orientadas a mejorar el componente morfosintáctico del lenguaje.23 2425 
Pérez R Ginna V, Martínez M Aura J, Peñaloza M Zayda R, Ortega O Yury K, Sinuco M Yulieth, Zambrano Laura B, Martínez O Jennyfer A.

-TICO: es una herramienta para generar y utilizar tableros de comunicación de forma interactiva y evitar así la construcción manual de dichos tableros se compone de dos aplicaciones, el Editor y el Intérprete. Con el Editor se crean los tableros que contendrán todos los elementos visuales, auditivos o de control de entorno. El sistema integra también una función de barrido que hace un recorrido secuencial por los elementos del tablero, lo que facilita el acceso a las personas que tienen trastornos graves en la motricidad.24

- Tableros de comunicación no electrónicos: Son las ayudas técnicas para la comunicación más sencillas, pueden construirse fácilmente con diferentes materiales: papel, cartón, plástico. son de gran utilidad en todas las alteraciones del lenguaje, según la necesidad específica, y de fácil acceso para los padres y terapeutas, además de que con el tiempo, mientras se ve mejora en el niño en los aspectos morfosintácticos, como realización de frases simples, se puede modificar, y aumentar su complejidad, por otro lado, sus símbolos se pueden acomodar a la edad del usuario y ser llamativos para este. 2223

- BEN: El Programa BEN trabaja con situaciones de la vida cotidiana y rutinas mediante la presentación de actividades en donde el niño debe secuenciar o elegir la opción adecuada. Se presentan situaciones en las que el niño debe optar por la reacción correcta lo que permite trabajar a nivel Pragmático y morfosintáctico.22 23

Con relación a las consideraciones anteriores el enfoque referente al uso de los equipos de comunicación para personas con discapacidad, ha permitido visualizar que esta población presenta generalmente problemas en la comunicación, hecho que reduce, de manera notable, las oportunidades de una interacción adecuada, la cual implica voluntad de interrelación con el otro y el manejo adecuado de códigos comunes, imprescindibles para la comprensión y la acción.25

A priori, el concepto de "desorden de comunicación" según Mora, se entiende, entonces, como toda limitación en la interacción comunicativa que puede traer como consecuencia una restricción en la participación de los roles y funciones que individuos o grupos tienen en la cultura y en la sociedad, y que involucran deficiencias en las capacidades y potencialidades del individuo para comunicar. Esto refiere, además; que las personas con discapacidad, presentan, además, impedimentos para desarrollar habilidades comunicativas y lingüísticas, a menudo la influencia negativa que el medio les proporciona al restringirles la exploración y la interacción con el entorno, la gente, la expresión de emociones, necesidades, pensamientos y el intercambio de información.26 Según Pierre Lévy (1998), la prevalencia de ciertas tecnologías - desarrolladas para asegurar al hombre superar los obstáculos naturales y la supervivencia con una mejor calidad de vida, en cada lugar y en cada tiempo - necesariamente dirige a la gente a un nuevo aprendizaje. Este aprendizaje no sólo está dirigido al dominio de determinados contenidos o habilidades específicas. Una manera amplia y compleja que determinan los valores, las acciones y la visión del mundo de cada persona y grupo social que vive. 27

Durante el proceso de búsqueda se evidencia que la implementación de software son generados a través de herramientas informáticas herramientas que apoyan diferentes ámbitos de aplicación en desórdenes de la comunicación humana. Estas herramientas facilitan la interacción o comunicación con el computador, las cuales resultan útiles en casos de discapacidad motriz; y, por otro lado, incluye una herramienta que permite crear actividades lúdicas para educación o intervención terapéutica y que pueden ser creadas por personas sin mayores conocimientos informáticos. Enable Viacam es un programa desarrollado por Cesar Mauri y su función es reemplazar el ratón físicamente, ya que mueve el puntero de este a partir del movimiento de la cabeza. Funciona en computadores con cámara web tradicional sin elementos adicionales. Switch Viacam es un emulador de interruptor basado en cámara web. Es decir, utilizando una cámara web es posible configurar un área concreta de la imagen (como una esquina), para que cuando dicha área cambie (como pasar la mano por la esquina) se active un evento de clic del ratón o la pulsación de una tecla. Dasher es una interfaz de entrada de texto, manejada por los movimientos continuos del puntero del ratón o joystick. Resulta muy útil en personas que no pueden usar un teclado normal-

42 mente o cuando los movimientos del usuario son muy limitados. En pantalla aparece un conjunto 
de letras que se van desplazando y que el usuario va seleccionando al acercar el puntero del ratón a dichas letras, luego, el sistema junta las letras para formar palabras y posteriormente mensajes, el conjunto de letras y palabras que alimentan el sistema se configura posteriormente a la instalación y, además, soporta varios idioma. Dasher tiene también la posibilidad de integrarse con un sistema de reconocimiento automático del habla y sintetizador de voz. Scratch es una herramienta que hace posible programar actividades interactivas, juegos y animaciones y compartirlos con otros usuarios en una comunidad en línea. Con esta herramienta, tal y como lo afirma Mitch Resnick, líder del grupo creador de Scratch: Lifelong Kindergarten del Laboratorio de Medios del Instituto Tecnológico de Massachusetts, se ayuda a jóvenes e interesados a "aprender a programar, a pensar creativamente, a razonar sistemáticamente y a trabajar colaborativamente".28

Es aquí donde el avance de las Nuevas Tecnologías hace un aporte invaluable en cuanto proporciona sistemas de ayuda, dirigidos a cubrir las necesidades expresivas y a aumentar la interacción comunicativa, tanto de personas que muestran un nivel elevado de comprensión del lenguaje, pero que carecen de un medio adecuado de expresión, como de aquéllas cuyos trastornos les han impedido adquirir el habla como vehículo de expresión y al mismo tiempo, el lenguaje comprensivo e incluso los requisitos cognitivos, sociales y lingüísticos, necesarios para la adquisición del lenguaje. Ello implica que los procesos de intervención e investigación, en el campo de la comunicación humana y sus desórdenes, deban hacerse desde una perspectiva sistémica, donde se integren y se relacionen todos los componentes con una visión de la comunicación como un fenómeno social en forma de espiral. Por lo tanto, se genera una nueva perspectiva de la comunicación como proceso dado desde la interacción, que incluye dimensiones de análisis en los niveles intrapersonal, interpersonal y sociocultural.29

Son muchos los autores como Pérez (2006), Tortosa (2004) entre otros, que hablan de las TIC como un buen elemento mediador para ayudar a los alumnos con algún trastorno del lenguaje a alcanzar un buen nivel de aprendizaje. Como Lehman, que nos dice que los alumnos con autismo prefieren trabajar con las TIC debido a su característico pensamiento visual. (Guerra Arango Carlos Fernando, Influencia del uso de las TIC en las prácticas formativas de los fonoaudiólogos. 2015.)30

Con base a otros estudios se logra determinar que la mayoría de estrategias implementadas con uso de TIC para mejorar los trastornos que se presentan a nivel fonético-fonológico, se presentan de una manera aislada y repetitiva, es decir algunas tratan de enseñar a través de la imitación de onomatopeyas y sonidos consonánticos los puntos y modos articulatorios con el fin de perfeccionarlos, otras trabajan praxias bucofaciales y proponen el juego como medio dinámico de aprendizaje. Con la implementación de esta estrategia se obtuvieron cambios relevantes en cuanto al repertorio fonético de dos de los sujetos intervenidos, en el otro con un trastorno del lenguaje más profundo se notaron cambios significativos en cuanto a su atención. Observando los resultados positivos que trae la implementación de la estrategia diseñada y logrando validarla de acuerdo a lo obtenido, se plantea continuar el proyecto en una siguiente fase la cual consistirá en diseñar un software basándose en los estímulos visuales y auditivos que tiene la estrategia.

\section{CONCLUSIONES}

De acuerdo a la búsqueda exhaustiva sobre el uso de equipos de comunicación para personas en situación de discapacidad desde el enfoque fonético-fonológico nos permite afirmar que el volumen de investigaciones donde se usan los sistemas de CAA es insuficiente, así mismo, se hace necesario seguir ahondando en la información respecto al uso de las herramientas de comunicación para personas en situación de discapacidad.

En efecto las herramientas mencionadas en este trabajo proporcionan a terapeutas diversas alternativas libres para intervención, además, promueven la implementación de competencias computacionales necesarias en los profesionales de la sociedad actual, por lo que se recomienda hacer más difusión de diseño de herramientas libres ya que contribuyen de una manera muy enriquecedora y sustancial al trabajo de los profesionales en esta área, como es el caso de fonoaudiólogos y educadores especiales. 
Pérez R Ginna V, Martínez M Aura J, Peñaloza M Zayda R, Ortega O Yury K, Sinuco M Yulieth, Zambrano Laura B, Martínez O Jennyfer A.

Con relación a la búsqueda de los artículos desde este enfoque cabe resaltar que la información hallada en el idioma español es insuficiente debido a que la mayoría de los artículos publicados se encuentran en idiomas extranjeros como inglés, francés y portugués dificultando de esta forma la revisión de los mismos.

Otro aspecto importante para resaltar en cuanto a la revisión es que la mayoría de las investigaciones realizadas se centran en población con déficit auditivo, siendo este sentido un elemento esencial para el aprendizaje, debido a que la pérdida auditiva dificulta la adquisición del lenguaje oral (receptivo y expresivo).

En cuanto al uso de las herramientas de comunicación para personas en situación de discapacidad se encontró que la mayoría de estos sistemas están diseñados solo para computadores y no son de libre acceso y/o gratuitos, por lo que se hace necesario implementar el uso de diseños de software para teléfonos celulares, Ipad y así mismo que sean forma gratuita, permitiendo con esto el fácil acceso a las mismas.

De acuerdo a lo anteriormente mencionado cabe resaltar que en la actualidad las instituciones educativas que acogen a personas con discapacidad auditiva no cuentan con herramientas suficientes que les faciliten a los niños el acceso a un aprendizaje significativo e incluyente.

En el campo de la semántica se han utilizado más mecanismos con tecnologías que medios didácticos para mejorar la comunicación. Se han implementado varias herramientas para personas con discapacidad, estos sistemas mejoran la comunicación y sirven como una ayuda esencial para el desarrollo de una buena calidad de vida en estas personas. Los artículos encontrados hablan sobre los dispositivos empleados para mejorar la comunicación aumentativa y alternativa en el campo de la semántica teniendo como parámetro el déficit cognitivo, debido a ser el mayor indicio en la población encontrada, se pudo observar que esta población es la que mayor dificultad tiene en este campo de la comunicación, algunas estrategias implementadas ha sido la utilización de tableros hospitalarios para una mejor comunicación entre paciente - enfermero, la utilización de dispografo que apoya el análisis psicolingüístico de los términos elicitados mediante encuestas de léxico disponible, la implementación de pictogramas que son utilizados con el fin de mejorar los sistemas de comunicación pero también se ha implementado estrategias didácticas mediante el juego de láminas para el desarrollo y evolución de esta problemática. Estableciendo un fin en los artículos encontrados lo cuales tiene como propósito generar modelos de comunicación que permiten ayudar a las personas que presentan alguna dificultad comunicativa.

Estableciendo que estas herramientas empleadas solo se han realizado para software, no se encontró un artículo como tal que nos hablara de un sistema utilizado en una APP, ni con otro déficit. Sería de gran ayuda implementar una aplicación para celular donde sea gratuito y de fácil acceso donde las personas con alguna alteración en su comunicación en el componente semántico puedan acceder a él, esto será de gran ayuda utilizando la tecnología, como se pudo observar en la actualidad es más fácil acceder a un teléfono móvil que a un computador.

El concepto de tecnología para la comunicación, utilizada en el habla hispana nos permitió iniciar con el proceso de definición de variables y cruces hacia las palabras claves para la realización de la búsqueda, e indagar su concepto en los descriptores utilizados como el Decs y MesH, esto da lugar a la importancia de encontrar palabras claves que permitan obtener una búsqueda màs completa, es decir, que se amplíe el concepto para no concluir que no se encuentra evidencia. Se encontró un descriptor de gran importancia para la realización de la búsqueda, que reemplazo la tecnología para la comunicación en Equipos de comunicación para personas con discapacidad. Los equipos de comunicación para personas con discapacidad, abarcan un campo muy amplio, pero de acuerdo a los hallazgos encontrados, se puede concluir que la información que se encuentra es muy escasa, sin embargo esta literatura se considera importante, ya que, los Equipos de comunicación para personas con discapacidad, son instrumentos que permiten un proceso de intercambio comunicativo, así mismo un medio de inclusión en diversas dimensiones, ya sea, social, personal, siendo la implementación de las tecnologías una nueva oportunidad de comunica-

44 ción para las personas con discapacidad. 
En el ámbito de la comunicación aumentativa y alternativa y el uso de las TIC, es posible encontrar diversas herramientas de gran utilidad que ayudan al profesional en fonoaudiología en el momento de la intervención, pero que además pueden acompañar al usuario durante su vida cotidiana, ayudando de manera más intensa en su proceso, y no solo en los 30 o 45 minutos de sesión terapéutica, por lo cual se lograran observar mejores resultados.

Gracias a los resultados obtenidos se logró identificar que para iniciar con la creación de un sistema de intervención que haga uso de las TIC y de la CAA, es indispensable la ayuda interdisciplinar de un profesional en ingeniería que tenga conocimientos acerca de programación, pues solo así se podrá crear un software.

Todos los seres humanos sin importar sus alteraciones comunicativas tienen derecho a comunicarse, y es nuestro deber como profesionales en fonoaudiología instruirnos continuamente en los avances tecnológicos e informáticos que nos guíen a una integra y favorable intervención.

\section{TRABAJOS CITADOS}

1. Espejo S, Carrillo A, Fernández A, Rodríguez M J. Estudio sobre el uso del sistema de comunicación aumentativo y aumentativo y alternativo. Departamento de lenguajes y sistemas informáticos de la universidad de granada. disponible en: https://dialnet.unirioja.es/servlet/articulo?código=3942517.

2. P. Pérez Pedraza, T. Salmerón López. Desarrollo de la comunicación y del lenguaje: indicadores de preocupación. Revista Pediatría de Atención Primaria Octubre/diciembre 2006; Volumen VIII. (Número 32.): disponible en:http://pap.es/files/1116-612-pdf/637.pdf

3. Gutiérrez R. Interacción de los Componentes del lenguaje oral, en El Proceso de Aprendizaje de la Lengua Escrita. (Internet) 2014; (citado el 25 de marzo del 2014) pp 31. disponible desde: www.eltallerdigital.com

4. Berko J. Bernstein N. Desarrollo del Lenguaje. edición. ciudad: editorial c2010. 147-149p. 5. William Ricardo Rodríguez Dueñas . "Appropiation of the information and communication technologies (ICTs) for the socialization of hearing-impaired persons. A case study: Zaragoza" . Pubmed 2015; 13(2): . http://www.scielo.org.co/pdf/recis/v13n2/v13n2a10.pdf (accessed 14 abril 2017).

6. Lázaro M. BACALLEO.. "Appropiation of the information and communication technologies (ICTs) for the socialization of hearing-impaired persons. A case study: Zaragoza"

Pubmed 2015; 28(1): . http://labrechadigital.org/labrecha/DOCS/zaragoza.pdf (accessed 14 abril 2017).

7. Hincapié I, M. G.. "Propiedades lingüísticas de los trastornos específicos del desarrollo del lenguaje". Redalyc 2007; http://publicaciones.konradlorenz.edu.co/index.php/rlpsi/article/ view/569 (accessed 8 marzo 2017).

8. Carlos Balboa Espinoza, N. M. "El desarrollo de la sintaxis en la adolescencia: posibles influencias de naturaleza social". Literatura y Lingüística (2012),http://www.scielo.cl/pdf/lyl/n25/ art08.pdf (accessed 5 marzo 2017)

9. Ferreras, U. L. . "La dimensión pragmática del signo literario". Scielo (2001 http://www. scielo.cl/scielo.php?script=sci_arttext\&pid=S0071-17132001003600004. (accessed 4 marzo 2017)

10. Salazar N, Ferrer Y; Toro I. Comunicación aumentativa y alternativa mediante tecnologías de apoyo para personas con discapacidad. Scielo (Internet). Universidad Pedagógica Nacional 2008 p. Disponible desd: http://www.pedagogica.edu.co/storage/ted/articulos/ted13_13arti.pdf (accessed 14 abril 2017).

11. Viviana Heguerte, M. J. (s.f.). Aplicación de las TICS en la intervención fonoaudiológica. scielo, (2008) http://www.niee.ufrgs.br/eventos/SICA/2008/pdf/C106\%20Fono.pdf (accessed 11 abril 2017)

12. Jiménez-Hernández, C. A.-S. Desarrollo tecnológico para el mejoramiento de la comunicación a distancia entre personas con discapacidad. Rev. salud pública, (2009) http://www.scielosp.org/pdf/rsap/v11n5/v11n5a16.pdf (accessed 15 abril 2017)

13. Vanegas J, Mejía F. La comunicación desde la lectura del lenguaje gestual en jóvenes en 
Pérez R Ginna V, Martínez M Aura J, Peñaloza M Zayda R, Ortega O Yury K, Sinuco M Yulieth,

Zambrano Laura B, Martínez O Jennyfer A.

situación de discapacidad auditiva. (Internet). 2012, Dic. (Citado el ...); 17(2). Disponible en: http:// www.scielo.org.co/scielo.php?script=sci_arttext\&pid=S0121-75772012000200008

14. González S, Gueorguieva R, Tijerino P. Capacitación sobre estrategias de comunicación alternativa y aumentativa para la atención de niños con parálisis cerebral infantil. (Revista electrónica). 2011, Ago. (Citado el...); Disponible en : https://dialnet.unirioja.es/servlet/articulo?codigo $=5021197$

15. Vega LI, Gràcia F. Los signos manuales como sistema de comunicación alternativa y aumentativa. Artículo de revisión. Revista Española de Discapacidad, 29-05-2014; (Citado el 20 de marzo de 2017): disponible en: https://dialnet.unirioja.es/descarga/articulo/4868186.pdf

16. William Ricardo Rodríguez Dueñas MsEng, PhD 1. Herramientas informáticas libres para los desórdenes de la comunicación humana. 17 de marzo de 2015; disponible en: http://www. scielo.org.co/pdf/recis/v13n2/v13n2a10.pdf

17. GarciaMV,NiñoAPT,CastellanosMFI,AnguloLMA,JuliaoILL.DIGITALIZACIÓNDEPROTOCOLOSDEEVALUACIÓNENELÁREADEHABLA,MEDIANTETECNOLOGÍASDEDESARROLLOWEBYAPLICACIONESWINDOWSQUECONTRIBUYANAMEJORARLAPRACTICIDADDELAAPLICACIÓN.RevCIENTÍFICA SIGNOS FÓNICOS [Internet].

18. TamaritJ. Educación inclusiva: trastornos del espectro delautismo. Formación en Red.(Internet).(citadoen1993).; módulo7.Disponibledesde:http://www.ite.educacion.es/formacion/materiales/185/cd/unidad_7/mo7_sistemas_alternativos.htm

19. De la Torre. El Lenguaje de los Símbolos Gráficos. $1^{\text {a }}$ ed. México; editorial Limusa; 1992. pág 71 -89

20. Maria Serrano, M. C. . Guía Metabólica. Obtenido de SJD: https://www.guiametabolica. org/consejo/sistemas-aumentativos-comunicacion-sac-errores-congenitos-metabolismo

21. Macías, E. M. "LOS SISTEMAS ALTERNATIVOS Y AUMENTATIVOS" . DIALNET(2010)., https://dialnet.unirioja.es/descarga/articulo/3391398.pdf (accessed 11 abril 2017)

22. Pérez, M. V. . Trastorno específico del lenguaje. Guía para la intervención en el ámbito educativo. Science Direct,(2014) http://www.ttmib.org/documentos/Guia_TEL.pdf. (accessed 11 abril 2017)

23. Consuelo Belloch, U. (4 de 4 de 2014). LAS TICs en logopedia: audiciòn y lenguaje. Obtenido de SAAC: https://www.uv.es/bellochc/logopedia/NRTLogo8.wiki?6 (accessed 11 abril 2017)

24. Nahir de Salazar, G. L. Comunicación aumentativa y alternativa. Universidad pedagogica nacional, (2000) http://www.pedagogica.edu.co/storage/ted/articulos/ted13_13arti.pdf (accessed 11 abril 2017)

25. Salazar N, Ferrer Y; Toro I. Comunicación aumentativa y alternativa mediante tecnologías de apoyo para personas con discapacidad. Scielo (Internet). Universidad Pedagógica Nacional 2008 p. Disponible desd: http://www.pedagogica.edu.co/storage/ted/articulos/ted13_13arti.pdf (accessed 14 abril 2017).

26. Portilla EMP, Tolosa MXM. Metodologías de Evaluación Fonoaudiológica del Componente Pragmático del Lenguaje en Infantes. Rev CIENTífICA SIGNOS FÓNICOS [Internet].

27. Revista Diálogo Educacional. "Aprendizagem mediada pela tecnologia Learning mediated by the technology". Revista Diálogo Educacional 2008; 4(10): 3.

28. QuiñónezYAS.Comunicación,EnvejecimientoySalud.RevCIENTÍFICASIGNOSFÓNICOS[Internet].

29. Carlos Alberto Calvache Mora. Perspectiva sistémica de la comunicación humana y sus desórdenes. Scielo (Internet) 2008. http://www.scielo.org.co/pdf/recis/v13n3/v13n3a01.pdf (accessed 14 abril 2017).

30. Lisbôa C, Bolli M, Freitas R. Trastorno fonológico: Aspectos de la producción, la percepción y la escritura. Revista Española de Discapacidad, diciembre 2010; vol.15(no.4): disponible en: http://www.scielo.br/scielo.php?script=sci_arttext\&pid=S1516-80342010000400013

Introducción | Hacer referencia Harvard | Hacer referencia a Vancouver | MHRA Referencing | Hacer referencia a OSCOLA | Otros sistemas | Glosario

(C) 2013 